\title{
On the meaning of peak temperature profiles in inverted metamorphic sequences
}

\author{
Sylvia Duprat-Oualid ${ }^{1,2,3,4}$ and Philippe Yamato ${ }^{2,3}$ \\ ${ }^{1}$ Department of Geodynamics and Sedimentology, University of Vienna, A-1090 Vienna, Austria. E-mail: sylvia.duprat.oualid@gmail.com \\ ${ }^{2}$ Université de Rennes 1, Géosciences Rennes, F-35042 Rennes cedex, France \\ ${ }^{3}$ CNRS, UMR 6118, F-35042 Rennes cedex, France \\ ${ }^{4}$ Université de Lorraine, UMR 7359 GéoRessources, F-54506 Vandoeuvre-lès-Nancy, France
}

Accepted 2017 March 23. Received 2017 March 21; in original form 2016 September 13

\section{S UMMAR Y}

Inverted metamorphic sequences (IMS) are common features of main thrust systems on Earth. They exhibit an upwards continuous increase in peak temperature conditions and thereby constitute evidence of the close relationship between the thermal field evolution and tectonic processes. Heat advection and shear heating are known to allow the formation of such metamorphic signatures. Heat diffusion also plays an important role in temperature distribution on both sides of the thrust. Other advection processes such as erosion or accretion may also cause a local peak temperature inversion. Each one of these processes therefore affects the thermal field around the thrust. However, despite the crucial importance of all these processes for the interpretation of the inverted peak temperature signatures, their respective influences have never been quantified and compared all together. To address this issue, we propose an innovative coupled approach. (i) We use two-dimensional numerical models that simulate various thrust systems, allowing for a wide diversity of setups. To illustrate this study, we focus on intracontinental thrust systems for which all processes listed are likely to play a key role in the thermal evolution. We perform a parametric study including kinematic settings (i.e. convergence, erosion and accretion), thermal properties, mechanical strength and heat sources. (ii) Dimensionless numbers based on parameters are used to quantify the relative contributions of each process to the thermal budget evolution. Hence, the three thermal processes (i.e. heat diffusion, heat advection and shear heating) are compared with each other via three dimensionless combinations of the Peclet and Brinkman numbers: $R_{\text {Dif }}, R_{\text {Adv }}$ and $R_{\text {Pro }}$, respectively. Erosion and accretion are compared separately, based on a fourth dimensionless number Rea. (iii) We analytically examine the inverted peak temperature recorded along profiles that are perpendicular to the thrust zone defined in our numerical experiments. Each peak temperature profile presenting an inversion can then be characterized by a function of approximation involving six meaningful parameters: the location $\mu_{\mathrm{FF}}$ and width $\sigma_{\mathrm{FF}}$ of the maximum peak temperature inversion, the characteristic peak temperature $T_{\text {cte }}$ and gradient $G_{\mathrm{LB}}$ beneath the inversion zone, and the inversion-related contrasts in the peak temperature $\Delta T$ and gradient $\Delta G$. This coupled approach, linking numerical modelling and analytical treatment, allows to quantitatively interpret IMS in terms of the processes involved. The application of our method to intracontinental thrust systems demonstrates that shear heating and erosion support significant inversions, but that the relative contributions of each process have meaningful consequences. Our results reveal that competition between shear heating and heat diffusion on the one hand, and between erosion and accretion on the other hand have a high impact. In particular, the variability in the rock's mechanical strength strongly influences the features of peak temperature inversions. Consequently, none of these processes can be ignored. 
Our results highlight the major importance of the rheology of rocks in the thermal evolution of shear zones. Finally, our methodology is not only restricted to the analysis of numerical data but also constitutes a way of broad interest to analyse peak temperature signatures around any shear zone.

Key words: Numerical approximations and analysis; Continental tectonics: compressional; Heat generation and transport; High strain deformation zones; Rheology: crust and lithosphere.

\section{INTRODUCTION}

Given that metamorphic rocks outcropping in major shear zones record the evolution of the physical conditions (i.e. pressure $P$ and temperature $T$ ) occurring in the tectonic plate boundaries during deformation, these rocks provide key constraints for our understanding of lithosphere dynamics. Within shear zone systems, variations in the $P-T$ records and deformation history are strongly linked because both the temperature and the state of stresses control the mechanical behaviour of rocks and consequently the intensity and distribution of the strain rate. Inverted metamorphic sequences (IMS), which correspond to sequences of rocks displaying a continuous increase in the metamorphism grade from bottom to top, and especially the inversion of metamorphic peak isotherms (i.e. the maximum temperatures to which the rocks are subjected), are generally used to decipher the context of the formation of certain major thrust zones. For instance, old oceanic subduction zones (e.g. the Franciscan Complex in western California) present kilometre-scale inversions of the peak temperatures with a downward gradient of $\sim 200$ ${ }^{\circ} \mathrm{C} \mathrm{km}^{-1}$ (e.g. Platt 1975; Graham \& England 1976; Graham \& Powell 1984; Peacock 1987; Kidder et al. 2013). Obduction zones are generally associated with the development of metamorphic soles in which an extreme inversion of the peak thermal gradients up to $1000{ }^{\circ} \mathrm{C} \mathrm{km}^{-1}$ can be reached (e.g. Williams \& Smyth 1973; Ghent $\&$ Stout 1981). Intracontinental collision systems can also exhibit IMS associated with major thrusts with inverted peak temperatures gradients up to $100{ }^{\circ} \mathrm{C} \mathrm{km}^{-1}$ or higher along several kilometres (e.g. Himalayas: e.g. Frank et al. 1973; Bollinger et al. 2004; Kohn, 2008, 2014; Law et al. 2013; Long et al. 2016; Variscan belt: e.g. Burg et al. 1984; Pitra et al. 2010; Caledonides: e.g. Andreasson \& Lagerblad 1980).

In this study, we specifically consider intracontinental collision systems as they are still subject to major debate in terms of the origins of IMS. Two hypotheses have been proposed to explain metamorphic inversions, which are applied to the Himalayan case most of the time. The first one suggests a post-metamorphic reversal of a pre-existing 'normal' sequence by crustal-scale overturned folding (e.g. Searle \& Rex 1989; Stephenson et al. 2000), or by passive deformation of metamorphic isograds either within a ductile shear zone (e.g. Jain \& Manickavasagam 1993; Grujic et al. 1996; Hubbard 1996; Gibson et al. 1999; Grasemann \& Vannay 1999) or by late thrusts cutting through the initial metamorphic sequence (e.g. Brunel \& Kienast 1986). The second hypothesis implies processes occurring simultaneously during shearing. With regards to this latter case, three major thermal processes can significantly affect the evolution of the thermal field and, consequently, the thermal inversion recorded in rocks:

(1) Advection: During thrusting, thermal inversion can be caused by nappe stacking of hot rocks above colder ones. This mechanism ('hot iron' effect) can be sufficient enough to produce a thermal inversion affecting both sides of the thrust (Le Fort 1975). Nevertheless, heat advection competes with heat diffusion, which thereby homogenises the temperature field. Convergence velocities with a high vertical component (typically $>0.5 \mathrm{~cm} \mathrm{yr}^{-1}$ ) increase the part of heat advection that allows for the development of a transient thermal inversion (England \& Molnar 1993; Duprat-Oualid et al. 2013). Metamorphic rocks from the whole downgoing lower block then record progressive heating and a thermal inversion. However, this record can only be preserved if the material is rapidly exhumed thereby preventing any thermal relaxation (i.e. if the exhumation rate is faster than the diffusion process at depth).

(2) Shear heating: Shear heating (Reitan 1968a,b) corresponds to local heat produced by the conversion of mechanical energy into heat within the thrust zone. This heat production cannot be ignored as it accounts for energy conservation (e.g. Brun \& Cobbold 1980; Scholz 1980). Within major shear zones, shear heating can rapidly (after a few Myr) produce a temperature increase of around one hundred degrees (e.g. Reitan 1968a; Graham \& England 1976; Scholz 1979; Brun \& Cobbold 1980; Brewer 1981; Pavlis 1986). Through heat diffusion, shear heating can contribute to thermal inversion at the top of the lower block (e.g. Arita 1983; England \& Molnar 1993) and can also be high enough to warm up the base of the upper block and to balance its cooling by nappe stacking (Nabelek et al. 2001, 2010; Duprat-Oualid et al. 2013; Nábělek \& Nábělek 2014).

(3) Radiogenic heat production: Radiogenic heat production constitutes an internal rock property that affects the whole crust. The presence of rocks highly enriched in radioactive elements within the upper block, amplified by an accretion and/or erosion process, can then lead to a more stable and significant thermal inversion via the 'hot iron' effect (Royden 1993; Huerta et al. 1996, 1998; Jamieson et al. 1998; Bollinger et al. 2006).

Both heat advection and shear heating are processes inherent to the shear zone activity whereas radiogenic heat production, accretion and erosion constitute thermal and kinematic variables of the system (e.g. Royden 1993). However, the relative contribution of all these processes on the distribution of metamorphic isograds around the thrust is still being debated and therefore needs to be clarified. Several theoretical, numerical and analytical studies have already addressed this problem of temperature evolution around thrust zones (e.g. Brewer 1981; Molnar \& England 1990; England \& Molnar 1993; Royden 1993; Duprat-Oualid et al. 2013, 2015). However, the metamorphic zonations do not necessarily correspond to the local instantaneous thermal field. Thermo-barometric and geochronology data reveal that two stacked units may have undergone different metamorphic histories (e.g. Copeland et al. 1991; Harrison et al. 1997; Goscombe \& Hand 2000; Catlos et al. 2001; DeCelles et al. 2001; Pitra et al. 2010; Patel et al. 2011; Mottram et al. 2014). In the past, some studies have focused on various $P-T-t$ paths interpretations in collisional orogens (e.g. England \& Thompson 1984; Shi \& Wang 1987; Jamieson et al. 1996), especially based on the example of the Himalayan case (e.g. Beaumont et al. 2001; Jamieson et al. 2004, 2006). Nevertheless, the variability in the inverted peak temperature zonations in relation to the 
(a) Simplified thrust systems

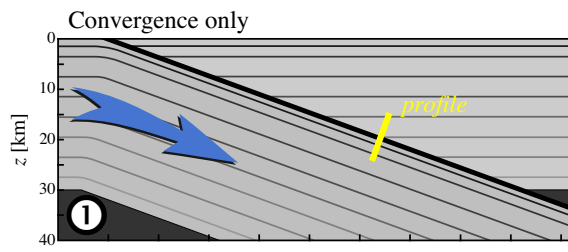

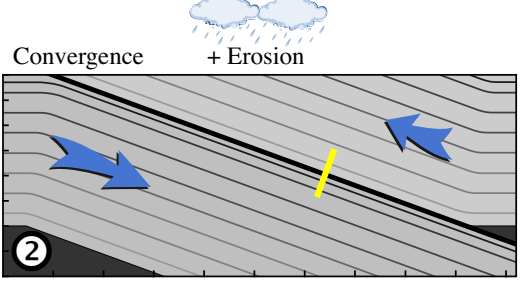

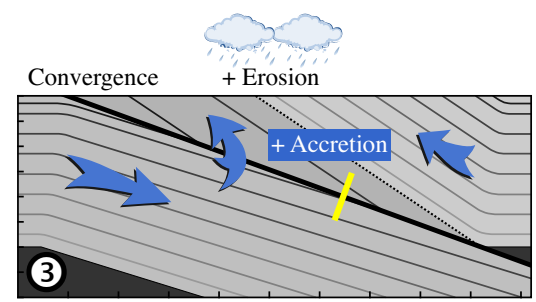

(b) Corresponding thermal profiles at $z_{f}=20 \mathrm{~km}$
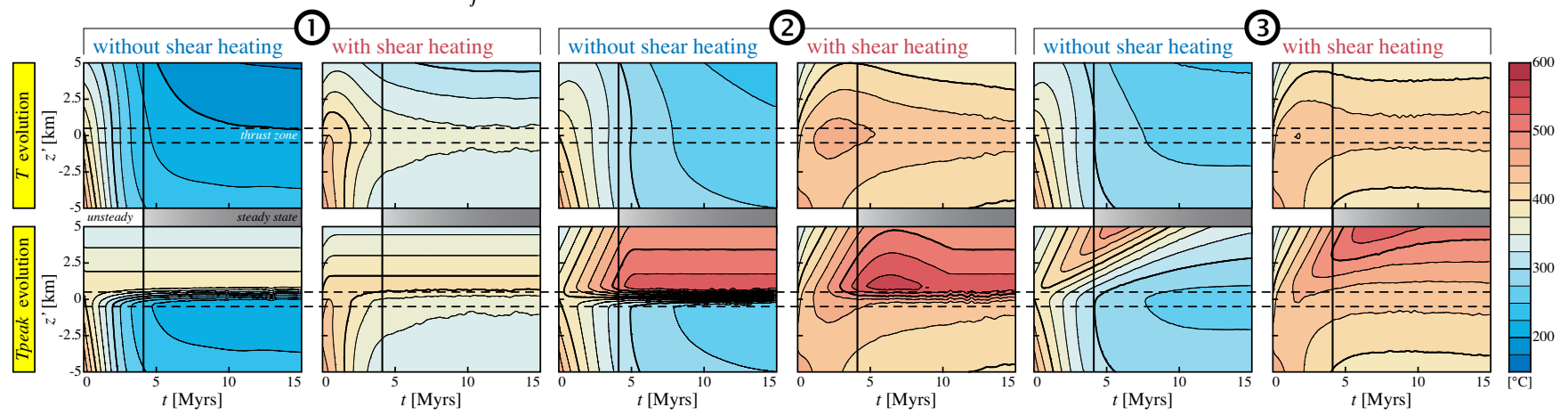

Figure 1. (a) General simplification of the thrust systems used in the numerical models presented in this study. Three different kinematic configurations are shown (blue arrows symbolize material trajectories) and allow the development of distinct structures. Case 1: pure convergence is ensured by the underthrusting of the lower block $\left(V=2 \mathrm{~cm} \mathrm{yr}^{-1}\right)$. Case 2: continuous frontal erosion allows the exhumation of the upper block $\left(e=2 \mathrm{~mm} \mathrm{yr}^{-1}\right)$. $V$ is then distributed on both sides of the thrust. Case 3: continuous accretion and erosion lead to the formation of an accretionary wedge presenting a constant exhumation $(a=2.5 \mathrm{~mm}$ $\mathrm{yr}^{-1}$ and $e=2 \mathrm{~mm} \mathrm{yr}^{-1}$ ). In the three diagrams, the yellow line shows the location of a 10-km-long profile perpendicular to the thrust and centred at a depth of $20 \mathrm{~km}\left(z_{f}\right)$ used in Fig. 1(b). (b) Evolution of the thermal profiles (from Fig. 1a) with time. The vertical axis $z^{\prime}$ represents the structural distance above the central axis of the thrust zone. The first line of diagrams shows the evolution of the instantaneous temperatures $T$. The second line displays the evolution of the peak temperatures $T_{\text {peak }}$. For each case, the left-hand column presents thermal evolutions without shear heating and the right-hand column shows results including shear heating (considering a constant effective viscosity $\eta=10^{20.25} \mathrm{~Pa}$ s across the $h=1$-km-thick thrust zone). Dashed lines indicate the thrust zone boundaries. It is assumed that a thermal steady state is reached after $4.1225 \mathrm{Myr}$ in all configurations (calculation taken from Molnar \& England 1990) and is represented by the vertical bold black lines.

variability in the whole range of possible kinematic and thermal processes has never been fully explored.

In this study, we will address this shortcoming. The aim here is to quantify the control of each previously described process and parameter on the development of an inverted metamorphic zonation around thrust zones. For this, we consider the thrust system as being as simple and adaptable as possible in order to account for the wide array of processes involved (i.e. heat advection, heat diffusion, heat production sources, accretion and erosion; Fig. 1a). We have designed a 2-D thermokinematic numerical model in which all these processes and kinematic configurations are expressed and can be controlled (see Section 3). Our study focuses on profiles placed perpendicularly to and centred on the thrust zone (Fig. 1a). These profiles can be used to track the evolution of the temperature field over time and, more precisely, the highest temperatures reached by the rocks (i.e. peak temperatures $T_{\text {peak }}$ ) as illustrated in Fig. 1(b). Then, $T_{\text {peak }}$ profiles displaying an inversion are analysed to reveal their distinctive features (e.g. location and intensity of the inversion). After this quantification, each one of these features can be correlated to the parameters and processes involved in each model. Finally, we discuss and highlight the applicability of our method to natural cases and how it can be used to better interpret IMS.

\section{METHODOLOGICAL STRATEGY}

To investigate the meaning of $T_{\text {peak }}$ profiles in IMS, we propose an analysis in three steps as follows (see Fig. 2).

\subsection{Numerical parametric study}

First, we carry out a parametric study by using a 2-D thermokinematical numerical model in which all parameters are controlled both in space and time (Duprat-Oualid et al. 2013). This enables us to test the influence of the parameters involved (i.e. thermal and kinematic processes) for predefined ranges of values related to intracontinental thrust systems (see Table 1). 4000 numerical simulations are performed with different combinations of randomly selected parameters. For each simulation, the contribution of the five active processes to the thermal evolution can be extracted and quantified by using specific dimensionless numbers (Fig. 2). These dimensionless numbers (see Section 3.4) are defined: (i) for the three thermal processes inherent to the thrust activity (i.e. heat diffusion, heat advection and shear heating; see Duprat-Oualid et al. 2015) and (ii) for the two additional kinematic processes (i.e. erosion and accretion).

One of the originalities of this study is the manner in which the results obtained in the numerical simulations are extracted. We focus on data extracted from our simulations along passive profiles located perpendicular to the thrust zone (Fig. 1a). These profiles provide an 'in-depth' view of the evolution of the physical conditions around the thrust during its activity. Here, we mainly focus on the thermal history of these profiles, especially in terms of the maximum temperature reached by the material (Fig. 1b). This defines what we refer to as the peak temperature profiles (or $T_{\text {peak }}$ profiles). As our main interest concerns the processes causing IMS, only the profiles displaying a local downward decrease in $T_{\text {peak }}$ closely associated with the active thrust zone are selected over time (Fig. 2). 


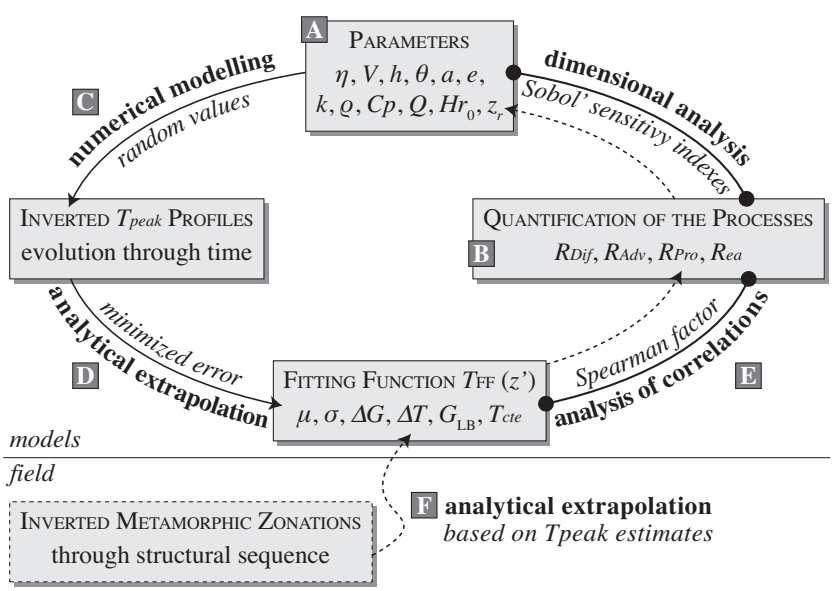

Figure 2. Schematic representation of the procedure highlighting our multiapproach methodology (shown as continuous tie lines and arrows) from [A] the parametric configuration (defining a thrust zone; Table 1) to [B] the analytically quantified contributions of the processes (Section 3.4). The combination of $[\mathrm{C}]$ numerical simulations with $[\mathrm{D}]$ the analytical treatment of their output (here the inverted $T_{\text {peak }}$ profiles; Section 5) is used to link [E] the observed inversion features with the contribution of the different processes (Section 6). The continuous analytical extrapolation of discrete peak temperature profiles also acts as an intermediary [F] between field-estimated metamorphic thermal fields and the in-depth processes at their origin which are themselves directly controlled by the parametric configuration (dashed lines and arrows).

\subsection{Analytical extrapolation of inverted $T_{\text {peak }}$ profiles}

Secondly, along the $T_{\text {peak }}$ profiles, the main features allowing the characterization of the metamorphic signature are: the spatial location and intensity of the $T_{\text {peak }}$ inverted gradient associated with the absolute $T_{\text {peak }}$ values. In order to quantitatively evaluate the relative contributions of the processes involved, these specific features therefore need to be extracted from the inverted $T_{\text {peak }}$ profiles. For this, we define a function of approximation involving six specific and meaningful parameters (Fig. 2). This general fitting function allows to accurately represent any inverted $T_{\text {peak }}$ profiles while using a minimum of relevant analytical parameters.

\subsection{Meaning of the inverted $T_{\text {peak }}$ profiles}

Finally, the features of the inverted $T_{\text {peak }}$ signatures obtained in our numerical models are compared to the contributions of the different processes involved (i.e. heat diffusion, heat advection, shear heating, erosion and accretion; Fig. 2). Their appearances and evolutions, in depth and time, are examined together with the evolution of the six fitting function parameters over the duration of each $T_{\text {peak }}$ inversion. This investigation provides first order keys to interpret IMS in terms of the thermal signal.

These three steps of our approach are described in detail in the following sections. Section 3 explains the technical aspects of the numerical model and the conversion of parametric combinations into process contributions. Section 4 details the definition of the $T_{\text {peak }}$ profiles and presents the method used to select the $T_{\text {peak }}$ profiles presenting an inversion. In section 5 , we present the analytical conversion of inverted $T_{\text {peak }}$ profiles into the fitting function. Section 6 is dedicated to the presentation of the results and summarizes the key points highlighting the meaning of the inverted $T_{\text {peak }}$ profiles. Finally, the content and implications of our method are discussed, especially with regards to its application to natural IMS.

\section{NUMERICAL MODELLING}

\subsection{Model, initial setup and velocity field computation}

The 2-D thermokinematic numerical model used for the parametric study is presented in Fig. 3(a). Our numerical code is based on the finite-difference method applied to a regular Eulerian staggered grid in which the marker-in-cell method is used to ensure the advection of material properties (Gerya \& Yuen 2003).

The numerical model, already fully described in Duprat-Oualid et al. (2013), is designed to simulate the convergence between two continental crustal blocks. The velocity field is calculated depending on shortening, erosion and accretion. The initial setup (Fig. 3a) represents a $z_{m}$-thick continental crust, located above the underlying lithospheric mantle, through which a thrust zone ensures the whole convergence with a constant velocity $V$. The active thrust is fixed and centred along the box width, and is characterized by a thickness $h$ and a dip angle $\theta$. Within the thrust zone, the strain rate is thus considered to be constant both in space and time. Erosion allows the exhumation of the upper block and is assumed to balance the tectonic uplift. Its velocity $e$ controls the distribution of the convergence velocity on each side of the thrust zone. The velocity $V$ is then broken down into $V_{\mathrm{UB}}$ and $\mathrm{V}_{\mathrm{LB}}$, corresponding to the velocity of the upper block and the velocity of the lower block, respectively, such as:

$\left\{\begin{array}{l}V_{\mathrm{UB}}=e \cdot \sin ^{-1}(\theta) \\ V_{\mathrm{LB}}=V-V_{\mathrm{UB}}\end{array}\right.$.

Table 1. Names, symbols and ranges of the values and units of the input parameters used in our numerical experiments.

\begin{tabular}{|c|c|c|c|c|c|}
\hline \multirow{2}{*}{$\begin{array}{l}\text { Symbol } \\
V\end{array}$} & \multirow{2}{*}{$\begin{array}{l}\text { Input parameter } \\
\text { Total convergence velocity }\end{array}$} & \multicolumn{3}{|c|}{ Range of tested values } & \multirow{2}{*}{$\begin{array}{l}\text { Unit } \\
\mathrm{cm} \mathrm{yr}^{-1}\end{array}$} \\
\hline & & 1 & to & 3 & \\
\hline$h$ & Thrust thickness & 1 & to & 3 & $\mathrm{~km}$ \\
\hline$\eta$ & Thrust effective viscosity & $1 \times 10^{19}$ & to & $1 \times 10^{21}$ & $\mathrm{~Pa} \mathrm{~s}$ \\
\hline$\theta$ & Thrust dip angle & 10 & to & 20 & $\circ$ \\
\hline$a$ & Horizontal accretion velocity & 0 & to & 2.5 & $\mathrm{~mm} \mathrm{yr}^{-1}$ \\
\hline$e$ & Vertical erosion velocity & 0 & to & 2.5 & $\mathrm{~mm} \mathrm{yr}^{-1}$ \\
\hline$k$ & Thermal conductivity & 2 & to & 4 & $\mathrm{~W} \mathrm{~m}{ }^{-1} \mathrm{~K}^{-1}$ \\
\hline$\rho$ & Density & 2500 & to & 3000 & $\mathrm{~kg} \mathrm{~m}^{-3}$ \\
\hline$C p$ & Heat capacity & 800 & to & 1200 & $\mathrm{~J} \mathrm{~kg}^{-1} \mathrm{~K}^{-1}$ \\
\hline$Q$ & Mantle heat flux & 20 & to & 40 & $\mathrm{~mW} \mathrm{~m}^{-2}$ \\
\hline$H r_{0}$ & Surface radiogenic heat production & 0 & to & 2 & $\mu \mathrm{W} \mathrm{m}^{-3}$ \\
\hline$z_{r}$ & Radioactivity specific depth & 5 & to & 25 & $\mathrm{~km}$ \\
\hline$z_{m}$ & Moho depth & 30 & to & 40 & $\mathrm{~km}$ \\
\hline
\end{tabular}


(a)

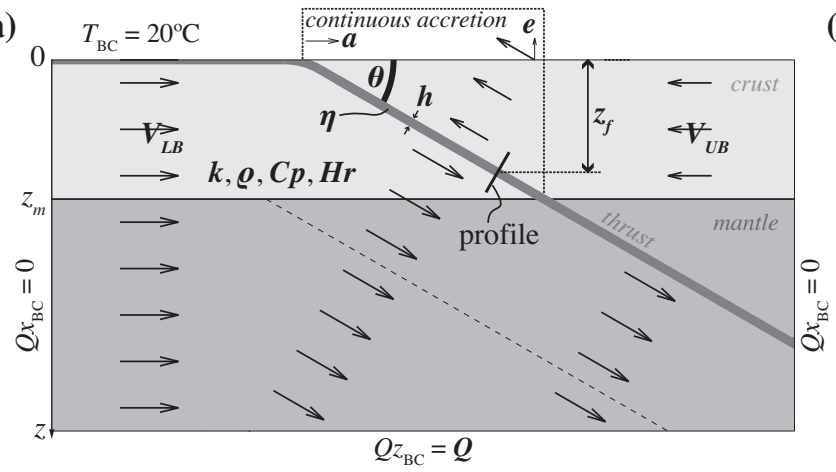

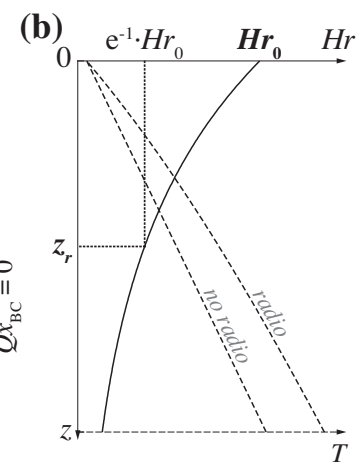

Figure 3. (a) Model setup presenting the $z_{m}$-thick continental crust and its underlying mantle submitted to a kinematic scheme simulating thrusting. The $h$-thick thrust zone, dipping with an angle $\theta$, ensures the convergence between the lower and upper continental blocks moving at velocities $V_{\mathrm{LB}}$ and $V_{\mathrm{UP}}$, respectively. $V_{\mathrm{UP}}$ is entirely controlled by the erosion velocity $e$. A constant accretion velocity $a$ is applied causing a continuous horizontal displacement of the crustal material through the thrust zone. Accretion is not represented in the velocity field inside the model box. The rheology of the thrust zone is simulated by the constant and homogeneous effective viscosity $\eta$. Thermal boundary conditions (BC) are also indicated. Insulating thermal boundary conditions are imposed on both lateral sides of the model. The surface temperature $T_{\mathrm{BC}}$ is fixed and a constant vertical mantle heat flux $Q$ is applied at the base ( $80 \mathrm{~km}$ depth). The thermal conductivity $k$, density $\rho$, heat capacity $C p$ and radiogenic heat production $H r$ constitute the internal thermal properties. (b) Initial thermal configuration. The radiogenic heat production $\mathrm{Hr}$ (upper horizontal axis) exponentially decreases with depth $z$ and is a function of $H_{0}$ and $z_{r}$. This controls the vertical thermal profile curvature (lower dashed horizontal axis). All input variables, highlighted in bold, are described in Table 1.

where $V$ and $e$ are independent variables even if $e$ is limited by the critical velocity $V \cdot \sin (\theta)$ because $V_{\mathrm{LB}} \geq 0$. Without surface denudation, the convergence is entirely ensured by the underthrusting of the lower block $\left(V=V_{\mathrm{LB}}\right)$.

The last kinematical parameter corresponds to the horizontal accretion velocity $a$ acting continuously along the thrust system (Fig. 3a). In our model, the active thrust zone is always located at a fixed position in the 2-D space represented in the model. The accretion vector $a$ thus simulates the transfer of material from the top of the lower block to the base of the upper block without any associated strain. Thus, the only strain location is the thrust zone.

\subsection{Computation of the thermal evolution}

The evolution of the temperature field $T$ in space with time $t$ is governed by the heat equation defined as:

$\rho C p \cdot\left(\frac{\partial T}{\partial t}+\overrightarrow{\mathbf{V}} \cdot \nabla T\right)=k \cdot \nabla^{2} T+H$,

where the density $\rho$, heat capacity $C p$ and thermal conductivity $k$ are internal rock properties, $\overrightarrow{\mathbf{V}} \cdot \nabla T$ corresponds to the advection of the temperature field by the velocity vector field $\overrightarrow{\mathbf{V}}$ and $H$ represents the heat sources term. Here, $H$ includes both shear heating $H s$ and radiogenic heat production $H r$. In our model, the thrust zone concentrates the whole strain rate and then constitutes the only source of shear heating:

$H s=\eta \cdot \frac{V^{2}}{h^{2}}$,

for which the effective viscosity $\eta$ is defined as a constant (i.e. the mechanical strength characterizing the whole thrust shear zone is considered to be homogeneous). This latter parameter is only used to calculate the shear heating term and to test, in the simplest manner, the consequences of its variability. $\mathrm{Hr}$ is defined depending on the static initial configuration according to the exponential law from Turcotte \& Schubert (2002, p. 141) defined as:

$H r(z)=H r_{0} \cdot \exp \left(\frac{-z}{z_{r}}\right)$, where $H r_{0}$ is the surface production and $z_{r}$ is a characteristic decay length (Fig. 3b). Before thrusting, thermal equilibrium is considered and then:

$T\left(z, t_{0}\right)=T_{\mathrm{BC}}+z \cdot \frac{Q}{k}+\frac{H r_{0} \cdot z_{r}^{2}}{k}\left[1-\exp \left(\frac{-z}{z_{r}}\right)\right]$.

In this eq. (5), both the surface temperature $T_{\mathrm{BC}}$ and mantle heat flux $Q$ are constants and define the thermal boundary conditions at both the top and base of the model box, respectively (Fig. 3a). Insulating boundary conditions are applied laterally.

\subsection{Choice of input parameters}

Thirteen input parameters defining the kinematic scheme and thermal conditions of the models are tested. They are highlighted in bold in Fig. 3. For each parameter, a realistic range of values for the general intracontinental thrusting is tested (see Table 1), and for the sake of consistency, is in agreement with known data from the emblematic case of the Main Central Thrust (e.g. Kohn et al. 2004 for velocities; Zhao et al. 1993; Kaneko et al. 2003 for the dip angle).

IMS are associated with major thrust systems. In collisional orogens, major thrusts are likely to localize most of the convergence velocity of the plates and consequently may be characterized by relative velocities between the two blocks of the order of one centimetre per year. In our models, the convergence velocity $V$ between the two blocks is accordingly set between 1 and $3 \mathrm{~cm} \mathrm{yr}^{-1}$. Values of the thrust zone dip angle $\theta$ between $10^{\circ}$ and $20^{\circ}$ are considered here as they could illustrate flat basal frontal thrust ramps. To simulate lithospheric-scale shear zones, kilometric thrust thicknesses $h$ are tested. Last, and to complete the kinematic scheme, the velocities for both continuous erosion $e$ and accretion $a$ are identically considered to range between 0 and $2.5 \mathrm{~mm} \mathrm{yr}^{-1}$.

The mechanical strength of the continental lithosphere as well as the distribution of the stresses and strain rates are still poorly constrained, and the effective viscosity $\eta$ is therefore a matter of debate (e.g. Burov 2003; Ranalli 2003; Afonso \& Ranalli 2004; Burov \& Watts 2006; Schmalholz et al. 2009). Here we test viscosities $\eta$ between $10^{19}$ and $10^{21} \mathrm{~Pa} \mathrm{~s}$ as a realistic first order range based on 
previous studies (e.g. Beaumont et al. 2004; Burg \& Gerya 2005; Duprat-Oualid et al. 2013).

For the intrinsic thermal properties of rocks, the thermal conductivity $k$ is considered to be between 2 and $4 \mathrm{~W} \mathrm{~m}^{-1} \mathrm{~K}^{-1}$ (Clauser $\&$ Huenges 1995; Turcotte \& Schubert 2002), the heat capacity $C p$ varies between 800 and $1200 \mathrm{~J} \mathrm{~kg}^{-1} \mathrm{~K}^{-1}$ (Waples \& Waples 2004) and the density $\rho$ of crustal rocks is widely taken as being between 2500 and $3000 \mathrm{~kg} \mathrm{~m}^{-3}$. For crustal rocks, radiogenic heat production $H r$ values are commonly in the order of $1 \mu \mathrm{W} \mathrm{m} \mathrm{m}^{-3}$ (e.g. Jaupart $\&$ Mareschal 2012) and may impact the initial thermal structure (eq. 5) with higher temperatures at depth (increment $>100{ }^{\circ} \mathrm{C}$ ) and a higher thermal gradient in shallow domains (increment of $\sim 10$ ${ }^{\circ} \mathrm{C} \mathrm{km}^{-1}$ ) depending on the $\left[\mathrm{Hr}_{0}, z_{\mathrm{r}}\right]$ values (Table 1). The mantle heat flux $Q$, which cannot be measured directly, is estimated from the surface heat flux and crustal radioactivity models (e.g. Pollack \& Chapman 1977; Artemieva \& Mooney 2001). A range of $Q$ values between 20 and $40 \mathrm{~mW} \mathrm{~m}^{-2}$ is considered here. Finally, the Moho depth $z_{m}$ is also considered to fall within a narrow range from 30 to $40 \mathrm{~km}$ in order to complete the panel of input variables and to estimate its implications on the obtained metamorphic thermal structure.

For this study, we perform 4000 numerical simulations in which the initial combinations of these 13 input parameters are randomly chosen (Table 1). According to Molnar \& England (1990), the thermal steady state is close to being reached when the time since the start of the thrust activity corresponds to the sum of two time constants related to advection and diffusion, respectively (see eqs 25 and 26 in Molnar \& England 1990). In this study, in agreement with Molnar \& England (1990), each simulation is run over $15 \mathrm{Myr}$ of convergence when all models have reached a thermal steady state along the entire thrust.

To investigate the impact of a set of parameters (Table 1) on the obtained results, a common method consists of testing each parameter, one by one, within its range of typical values by keeping all the others constant. This method can only be applied if the variability in the output signal corresponds to an easily definable law of dependency (e.g. by a linear function) and if the input parameters are independent. However, even if the input parameters are considered to be independently controlled, it is not easy to apply this method in this study for two main reasons: (i) too many parameters are tested (Table 1) and (ii) the output $T_{\text {peak }}$ profiles have to be analysed according to various features (occurrence, timing, intensity, location of the inversion and absolute $T_{\text {peak }}$ values).

Therefore, instead of directly analysing the 13 input parameters, we consider the five processes involved by the parametric combination (i.e. heat diffusion, heat advection, shear heating, erosion and accretion). The main advantage is to correlate fewer input elements to the output signals. Furthermore, one parameter may be involved in several processes (e.g. $V$ in heat advection and shear heating). The ability to quantify the contributions of the processes (see next Section 3.4) thus provides new meaningful general clues for the interpretation of IMS.

\subsection{Definition of the dimensionless numbers}

For the thermal processes, the Peclet number $P e$ establishes the ratio of advection over diffusion and the Brinkman number $\mathrm{Br}$ quantifies the relative importance of viscous dissipation over heat diffusion:

$P e=\frac{h \cdot V \cdot \sin (\theta)}{\kappa}$ and $B r=\frac{z_{f} \cdot \eta \cdot V^{2}}{h \cdot T_{0} \cdot k}$, where $\kappa$ is the thermal diffusivity and $T_{0}$ is the initial temperature at depth $z_{\mathrm{f}}$ (eq. 5). As defined in Duprat-Oualid et al. (2015), Pe and $\mathrm{Br}$ can then be used to define three dimensionless numbers $R_{\text {Dif }}, R_{\mathrm{Adv}}$ and $R_{\text {Pro }}$ which are useful in the quantification of the relative contributions of diffusion, advection and shear heating to the thermal budget of a thrust zone:

$\left\{\begin{array}{l}R_{\mathrm{Dif}}=\frac{1}{P e+1+B r} \\ R_{\mathrm{Adv}}=\frac{P e}{P e+1+B r} \\ R_{\mathrm{Pro}}=\frac{B r}{P e+1+B r}\end{array}\right.$.

However, these dimensionless numbers do not take accretion $a$ and erosion $e$ into account (eq. 6), which have to be considered separately. Accretion implies successive thrust zones throughout the convergence duration and therefore corresponds to an additional singular process (for the sake of simplicity, we do not differentiate frontal $v s$ basal accretion and only consider a first order constant accretion, see Section 3.1, and Figs 1a and 3a). Erosion controls the partitioning of the total convergence velocity between the two blocks (eq. 2) and has an impact on the thermal boundary conditions of the thrust. An increase in $e$ results in the rocks from the upper block reaching the surface faster (and leads to a slower underthrusting of the rocks from the lower block). Furthermore, both accretion and erosion do not result in any strain overprint and consequently do not produce additional shear heating. Because both $a$ and $e$ are introduced as velocities (same unit), their relative importance can be quantified by defining an additional dimensionless number $R_{\text {ea }}$ such as:

$R_{\mathrm{ea}}=\frac{e}{e+a}$.

Hence, the value of $R_{\text {ea }}$ ranges between 0 (accretion domination) and 1 (erosion domination).

The ranges of values for each input parameter obviously impact the ranges of the contributions of the processes. To look at the sensitivity of the range of $R_{\text {Dif }}, R_{\mathrm{Adv}}$ and $R_{\text {Pro }}$ with regards to the invoked input parameters, the statistical Sobol' index of first order global sensitivity (Sobol' 1990) can be used (Fig. 2). The Sobol' indexation is used to obtain a quantified ordering of the correlations between the parameters and processes. In particular, it is possible to distinguish the most influential parameters on the variability of each process contribution. This statistical tool and its application within the framework of our study are presented in detail in Appendix A.

\section{PEAK TEMPERATURE PROFILES AND INVERSION}

To follow the evolution of the maximum temperatures reached by the rocks around the thrust, peak temperatures $T_{\text {peak }}$ are extracted from our models along profiles that are perpendicular to the thrust (Figs 1b,c and 3a). This section presents this extraction procedure and how the inverted $T_{\text {peak }}$ profiles are selected.

\subsection{Extraction of $T_{\text {peak }}$ profiles from 2-D models}

The $T_{\text {peak }}$ profiles are extracted along a $10 \mathrm{~km}$-long profile perpendicular to the shear direction and centred at a depth $z_{f}$ across the thrust (Fig. 3a). The $T_{\text {peak }}$ values reached all along this profile during each experiment are recorded through time (i.e. for each time step). This profile is comprised of static markers spaced at $100 \mathrm{~m}$ intervals, the space location of which is characterized by the structural distance $z^{\prime}$ above the central axis of the thrust 


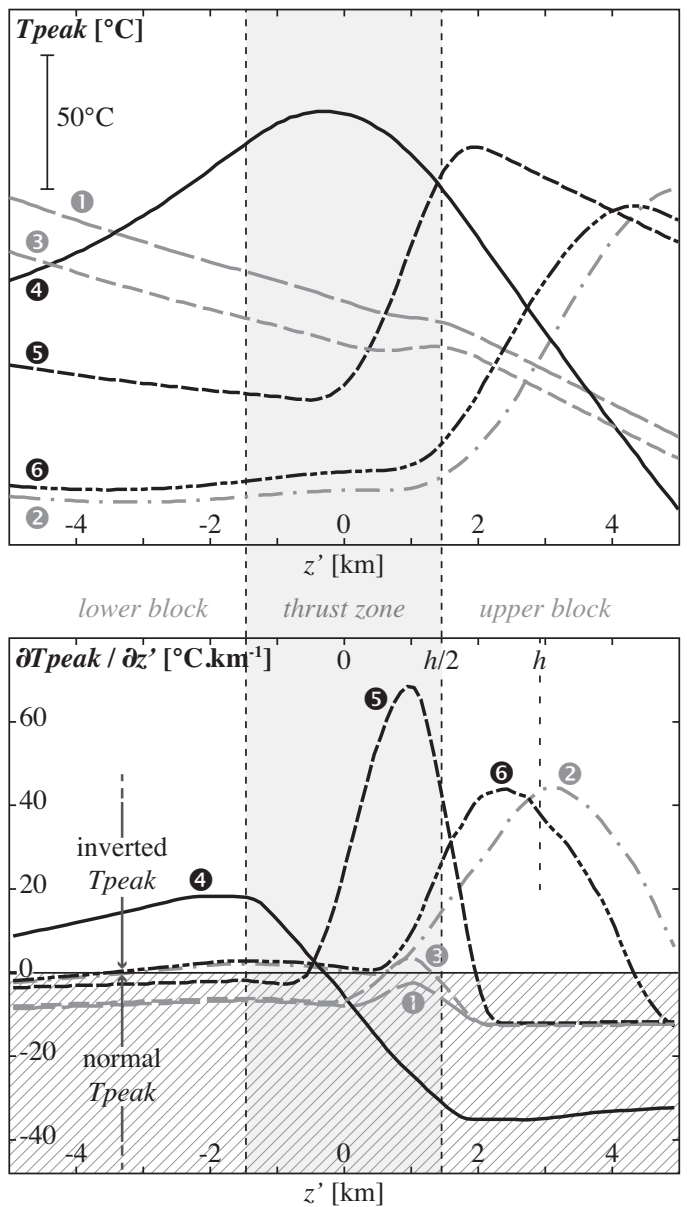

Figure 4. Six examples of $T_{\text {peak }}$ profiles (upper diagram) and their corresponding structural gradients $\partial T_{\text {peak }} / \partial z^{\prime}$ (lower diagram) illustrating the conditions for the selection of 'valid' inverted $T_{\text {peak }}$ profiles. The light grey area encompasses the $h$-thick thrust zone. In the lower diagram, the domain of negative structural $T_{\text {peak }}$ gradients (i.e. normal peak temperature trend with $T_{\text {peak }}$ increasing downwards) is shown in the hatched area. Positive $\partial T_{\text {peak }} / \partial z^{\prime}$ values indicate local inverted peak temperature trends (i.e. $T_{\text {peak }}$ increasing upwards). The three grey profiles do not match with at least one of the conditions required: Case 1, no inversion all along the $z^{\prime}$-axis (condition 1 failed); Case 2, a local $T_{\text {peak }}$ inversion occurs but far from the thrust zone (condition 2 failed); Case 3, the mean $T_{\text {peak }}$ in the lower block is higher than the mean $T_{\text {peak }}$ within the thrust zone (condition 3 failed). The three black profiles Cases 4, 5 and 6 show different 'valid' inverted $T_{\text {peak }}$ profiles selected for further analysis. Their perturbation maxima $\left(\max \left(\partial T_{\text {peak }} / \partial z^{\prime}\right)\right)$ are located in the lower block, within the thrust zone and in the upper block, respectively.

zone $\left(z^{\prime}>0\right.$ corresponds to markers located in the upper block and $z^{\prime}<0$ to markers located in the lower block). $T_{\text {peak }}$ profiles through time are analysed for different depths $z_{\mathrm{f}}$ for all 4000 experiments performed.

\subsection{Criteria for the selection of inverted $T_{\text {peak }}$ profiles}

Only $T_{\text {peak }}$ profiles presenting an inversion are selected. This selection is based on the strict union of the three following conditions (Fig. 4):

(1) The maximum value of the peak temperature gradient $\left(\partial T_{\text {peak }} / \partial z^{\prime}\right)$ must be positive (i.e. $T_{\text {peak }}$ increasing upwards). This corresponds to the definition of a local inversion.
(2) The point of maximum $T_{\text {peak }}$ inversion must be located within the thrust vicinity (i.e. $\left|z^{\prime}\right| \leq h$ ) as natural cases of IMS generally occur close to the shear zone (see Section 1).

(3) The mean $T_{\text {peak }}$ within the undeformed lower block (i.e. $\left.z^{\prime}<-h / 2\right)$ must be colder than the mean $T_{\text {peak }}$ within the thrust zone (i.e. $\left|z^{\prime}\right| \leq h / 2$ ). This is not a sine qua non condition but it provides evidence for the presence of a significant metamorphic thermal inversion, particularly if the lower block is characterized by a normal $T_{\text {peak }}$ gradient (i.e. $\partial T_{\text {peak }} / \partial z^{\prime}<0$ ).

Three examples of $T_{\text {peak }}$ profiles that do not match each of these three conditions listed above are presented in Fig. 4 (Cases 1, 2 and 3). Conversely, Cases 4, 5 and 6 (Fig. 4) show three profiles that match all three criteria. However, these three 'valid' $T_{\text {peak }}$ profiles highly differ from each other in terms of the location, width and intensity of their inversion. This is the reason why a special analytical extrapolation of these profiles is required to characterize these different features.

\section{ANALYTICAL EXTRAPOLATION OF INVERTED PEAK TEMPERATURE PROFILES}

\subsection{Construction of the general fitting function $T_{\mathrm{FF}}$}

The previously selected inverted $T_{\text {peak }}$ profiles can highly differ depending on the intensity or space location of the inversion, for instance (e.g. Figs 1c and 4). In order to characterize these different features from the shapes of these $T_{\text {peak }}$ profiles, the most powerful method consists of fitting the $T_{\text {peak }}$ profiles using analytical extrapolations associated with the lowest error (in the order of a few ${ }^{\circ} \mathrm{C}$ ). The construction of this function $T_{\mathrm{FF}}$ is made on the basis of a unique general fitting function of $z^{\prime}$ as follows:

(1) The general extrapolation of the inverted $T_{\text {peak }}$ profiles requires a non-linear expression of a local change in the trend (i.e. the gradient along the structural profile), taking the variable intensity and different spatial distribution into account. Hence, we based the whole analytical development on normal distribution laws that directly allow to specify either the space location of the perturbation or thermal characteristics. An analytical function $T_{\mathrm{FF}}$ can thus be expressed by the following cumulative distribution function (Fig. 5a, red curve):

$T_{\mathrm{FF}}\left(z^{\prime}\right)=\frac{\Delta T}{2} \cdot\left[1+\operatorname{erf}\left(\frac{z^{\prime}-\mu_{\mathrm{FF}}}{\sigma_{\mathrm{FF}} \sqrt{2}}\right)\right]+T_{\mathrm{cte}}$,

where the mean $\mu_{\mathrm{FF}}$ represents the maximum $T_{\text {peak }}$ inversion point (Fig. 5b). The standard deviation $\sigma_{\mathrm{FF}}$ characterizes the lateral extension of the inversion along the structural axis $z^{\prime} . T_{\text {cte }}$ is a constant corresponding to the plateau temperature within the lower block (i.e. $z^{\prime} \rightarrow-\infty$ ) and $\Delta T$ controls the temperature difference between the two plateaus (i.e. $T_{\mathrm{FF}}\left(z^{\prime} \rightarrow-\infty\right)-T_{\mathrm{FF}}\left(z^{\prime} \rightarrow+\infty\right)$; see Fig. 5a). The term erf corresponds to the error function.

The corresponding structural gradient, that is the derivative through the $z^{\prime}$-axis (Fig. 5b, red curve), then follows a probability distribution function such as:

$\frac{\partial T_{\mathrm{FF}}}{\partial z^{\prime}}\left(z^{\prime}\right)=\Delta T \cdot \frac{1}{\sigma_{\mathrm{FF}} \sqrt{2 \pi}} \cdot \exp \left(\frac{\left(z^{\prime}-\mu_{\mathrm{FF}}\right)^{2}}{2 \sigma_{\mathrm{FF}}^{2}}\right)$.

(2) To consider different thermal gradients on either side of the inversion zone, a specific term $G_{\text {add }}$ is added in eq. (10). $G_{\text {add }}$ is 


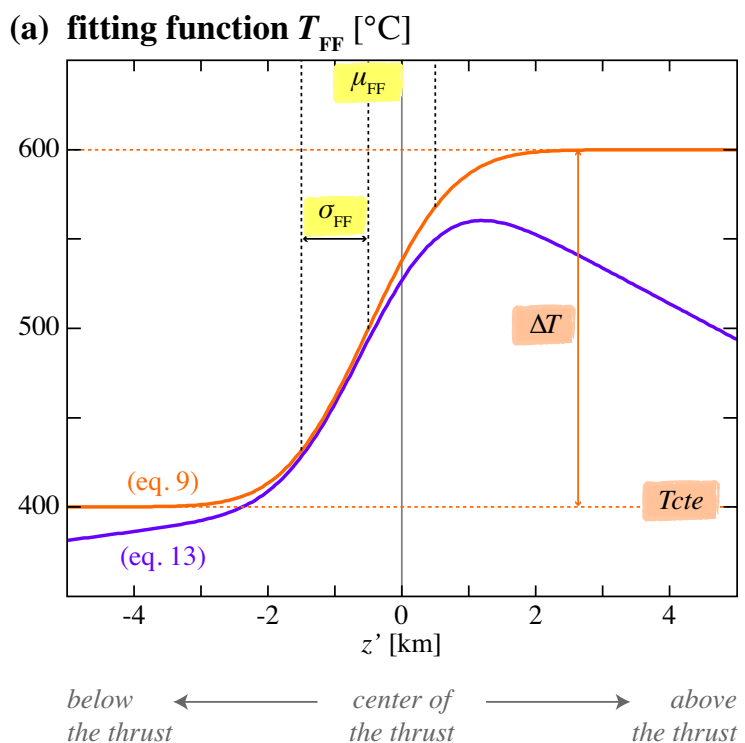

(b) structural gradient $\partial T_{\mathrm{FF}} / \partial z^{\prime}\left[{ }^{\circ} \mathrm{C} \cdot \mathrm{km}^{-1}\right]$

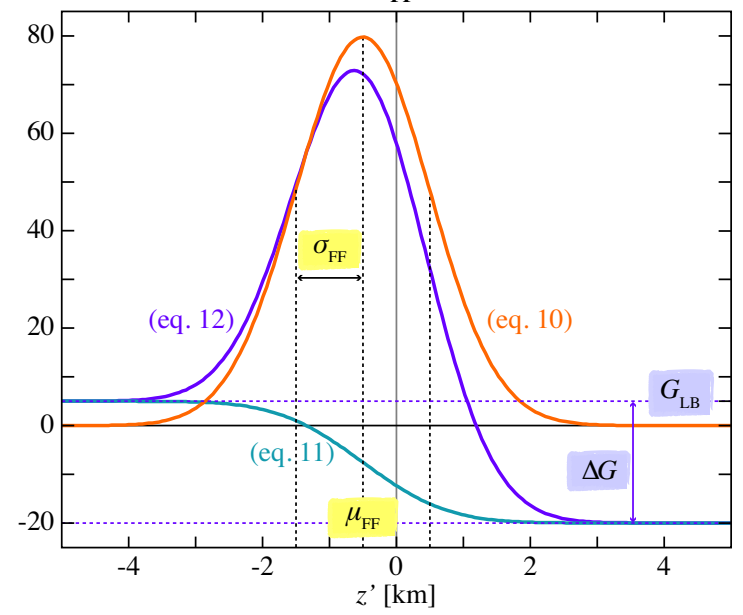

Figure 5. (a) Thermal fitting function $T_{\mathrm{FF}}\left(z^{\prime}\right)$ and (b) associated structural gradient $\partial T_{\mathrm{FF}} / \partial z^{\prime}\left(z^{\prime}\right)$. The six parameters involved $\left[\mu_{\mathrm{FF}}, \sigma_{\mathrm{FF}}, T_{\mathrm{cte}}, \Delta T, G_{\mathrm{LB}}\right.$, $\Delta G]$ are highlighted by different background colours (yellow for the space location parameters $\mu_{\mathrm{FF}}$ and $\sigma_{\mathrm{FF}}$; red for temperature parameters $\Delta T$ and $T_{\text {cte }}$; blue for thermal gradient parameters $\Delta G$ and $G_{\mathrm{LB}}$ ). In both diagrams, the red curve corresponds to a fitting function considering $T_{\mathrm{FF}}$ plateaus for the two sides of the inversion zone (eqs 9 and 10, respectively). When an additional structural gradient is considered (eq. 11), the resulting fitting function is represented by blue curves (eqs 12 and 13). For both fitting functions (red and blue), the six parameters used are summarized in Table 2.

chosen in line with the normal distribution trends to respect the continuity of $\partial T_{\mathrm{FF}} / \partial z^{\prime}$ such as:

$G_{\text {add }}\left(z^{\prime}\right)=\frac{\Delta G}{2} \cdot\left[1+\operatorname{erf}\left(\frac{z^{\prime}-\mu_{\mathrm{FF}}}{\sigma_{\mathrm{FF}} \sqrt{2}}\right)\right]+G_{\mathrm{LB}}$,

where $G_{\mathrm{LB}}$ sets the metamorphic thermal gradient in the lower block far from the inversion zone (i.e. $z^{\prime} \rightarrow-\infty$ ) and $\Delta G$ is its difference with the upper block value (i.e. $z^{\prime} \rightarrow+\infty$ ) (Fig. 5b, thin blue coloured curve). Accordingly, $G_{\text {add }}$ represents the continuous transition between the two domains of constant and different $T_{\text {peak }}$ gradients. Both the mean and standard deviation are chosen in agreement with eqs (9) and (10), thereby limiting the number of unknowns. The final expression of the structural $T_{\mathrm{FF}}$ gradient (Fig. 5b, blue curve) is obtained by summing eqs (10) and (11), and becomes:

$$
\begin{aligned}
\frac{\partial T_{\mathrm{FF}}}{\partial z^{\prime}}\left(z^{\prime}\right)= & \frac{\Delta G}{2} \cdot\left[1+\operatorname{erf}\left(\frac{z^{\prime}-\mu_{\mathrm{FF}}}{\sigma_{\mathrm{FF}} \sqrt{2}}\right)\right] \\
& +\Delta T \cdot \frac{1}{\sigma_{\mathrm{FF}} \sqrt{2 \pi}} \cdot \exp \left(\frac{\left(z^{\prime}-\mu_{\mathrm{FF}}\right)^{2}}{2 \sigma_{\mathrm{FF}}^{2}}\right)+G_{\mathrm{LB}},
\end{aligned}
$$

Through the integration of eq. (12), the final thermal function $T_{\mathrm{FF}}$ (Fig. 5a, blue curve) is defined by:

$$
T_{\mathrm{FF}}\left(z^{\prime}\right)=\left\{\begin{array}{rl}
\frac{\Delta G}{2} \cdot & {\left[z^{\prime}+\left(z^{\prime}-\mu_{\mathrm{FF}}\right) \cdot \operatorname{erf}\left(\frac{z^{\prime}-\mu_{\mathrm{FF}}}{\sigma_{\mathrm{FF}} \sqrt{2}}\right)\right.} \\
+ & \left.\sigma_{\mathrm{FF}} \cdot \sqrt{\frac{2}{\pi}} \cdot \exp \left(-\frac{\left(z^{\prime}-\mu_{\mathrm{FF}}\right)^{2}}{2 \sigma_{\mathrm{FF}}{ }^{2}}\right)\right] \\
+\frac{\Delta T}{2} \cdot\left[1+\operatorname{erf}\left(\frac{z^{\prime}-\mu_{\mathrm{FF}}}{\sigma_{\mathrm{FF}} \sqrt{2}}\right)\right]+G_{\mathrm{LB}} \cdot z^{\prime}+T_{\mathrm{cte}}
\end{array} .\right.
$$

The fitting function $T_{\mathrm{FF}}$ therefore involves the six unknown parameters defined above $\left[\mu_{\mathrm{FF}}, \sigma_{\mathrm{FF}}, T_{\text {cte }}, \Delta T, G_{\mathrm{LB}}, \Delta G\right]$ (Table 2). Compared to the first expression of $T_{\mathrm{FF}}$ (eq. 9), the mean $\mu_{\mathrm{FF}}$ in eq. (13) does not strictly express the location of the maximum inversion but corresponds to an approximation of it. Similarly, $T_{\text {cte }}$ does not correspond to a thermal plateau value in the lower block (Fig. 5) as in eq. (9).

\subsection{Application of the general fitting function $T_{\mathrm{FF}}$}

Each $T_{\text {peak }}$ profile extracted from our model (Section 3) that displays an inversion (Section 4.2) is used to extract the six parameters $\left(\mu_{\mathrm{FF}}, \sigma_{\mathrm{FF}}, T_{\mathrm{cte}}, \Delta T, G_{\mathrm{LB}}\right.$ and $\Delta G$ ) of the fitting function $T_{\mathrm{FF}}$. For this, the nlinfit Matlab function is used. This function approximates by iterations a data signal with a predefined set of parameters (eq. 13). In order to illustrate this, five numerical simulations presenting clear distinct combinations of process contributions (Fig. 6a) and specific $T_{\text {peak }}$ inversions (Fig. 6b, left-hand columns) are chosen. For each case, the middle columns in Fig. 6(b) show the continuous fitting functions $T_{\mathrm{FF}}$ resulting from the conversion of each inverted discrete $T_{\text {peak }}$ profile extracted from our numerical experiments. The associated absolute error, that is the difference between $T_{\text {peak }}$ values coming from the models and the analytical fit, is very low (quasi-systematically $\sim 1{ }^{\circ} \mathrm{C}$, rarely more than $10{ }^{\circ} \mathrm{C}$; see Fig. $6 \mathrm{~b}$, right-hand columns). This difference represents a relative error in the order of 1 per cent. We therefore consider that the fitting function $T_{\mathrm{FF}}$ constitutes a good representation of the inverted $T_{\text {peak }}$ profiles produced numerically.

Finally, the analytical fitting function $T_{\mathrm{FF}}$ allows to approximate any inverted $T_{\text {peak }}$ profile resulting from all of the numerical experiments based on the random combination of the 13 input parameters (Table 1). This unique function only uses six parameters (Table 2), the variability of which controls the $T_{\text {peak }}$ signature in the vicinity of the thrust zone. From this, it is now possible to quantify the relationships between the different acting processes (heat diffusion, heat advection, shear heating, erosion and accretion) and the diverse characteristics of inverted $T_{\text {peak }}$ profiles.

\subsection{Statistical analysis}

The input parameters (Table 1) are disproportionally involved in both the general heat equation (Section 3.2) and the contributions of the processes (Section 3.4). Consequently, there is no reason to find a proportional correlation between the processes and features 
Table 2. Values of the six fitting function parameters chosen for the theoretical illustrations of Fig. 5 and for the application presented in Fig. 6 (mean \pm standard deviation). These six parameters are: the location $\mu_{\mathrm{FF}}$ and width $\sigma_{\mathrm{FF}}$ of the maximum peak temperature inversion, the characteristic peak temperature $T_{\text {cte }}$ and gradient $G_{\mathrm{LB}}$ beneath the inversion zone, the inversion related contrasts of peak temperature $\Delta T$ and gradient $\Delta G$.

\begin{tabular}{|c|c|c|c|c|c|c|}
\hline & $\mu_{\mathrm{FF}}(\mathrm{km})$ & $\sigma_{\mathrm{FF}}(\mathrm{km})$ & $T_{\text {cte }}\left({ }^{\circ} \mathrm{C}\right)$ & $\Delta T\left({ }^{\circ} \mathrm{C}\right)$ & $G_{\mathrm{LB}}\left({ }^{\circ} \mathrm{C} \mathrm{km}^{-1}\right)$ & $\Delta G\left({ }^{\circ} \mathrm{C} \mathrm{km}^{-1}\right)$ \\
\hline \multicolumn{7}{|c|}{ Theoretical values used in Fig. 5} \\
\hline Red & -0.5 & 1 & 400 & 200 & 0 & 0 \\
\hline Blue & -0.5 & 1 & 400 & 200 & 5 & -25 \\
\hline \multicolumn{7}{|c|}{ Examples of application (see Fig. 6) } \\
\hline Case 1 & $0.68 \pm 0.14$ & $0.50 \pm 0.06$ & $281 \pm 14$ & $135 \pm 22$ & $-2.26 \pm 0.56$ & $-10.5 \pm 0.6$ \\
\hline Case 2 & $2.23 \pm 0.48$ & $0.84 \pm 0.13$ & $305 \pm 18$ & $96 \pm 24$ & $1.05 \pm 0.63$ & $-12.6 \pm 3.8$ \\
\hline Case 3 & $-0.88 \pm 0.08$ & $1.12 \pm 0.12$ & $567 \pm 32$ & $71 \pm 10$ & $18.95 \pm 5.09$ & $-48.9 \pm 4.2$ \\
\hline Case 4 & $0.18 \pm 1.02$ & $0.73 \pm 0.34$ & $564 \pm 98$ & $30 \pm 34$ & $18.81 \pm 4.56$ & $-42.7 \pm 4.8$ \\
\hline Case 5 & $1.52 \pm 0.08$ & $0.70 \pm 0.18$ & $364 \pm 8$ & $91 \pm 44$ & $3.83 \pm 1.42$ & $-18.2 \pm 2.5$ \\
\hline
\end{tabular}

of the inverted $T_{\text {peak }}$ profiles. Nevertheless, the predominance of one process in one feature will be expressed by a single positive or negative correlation. For this, Spearman's correlation coefficient, which reveals monotonic interdependencies regardless of their linear or non-linear character, can be used. Spearman's rank correlation coefficient $r_{S}$ is based on the ranked variables (i.e. the position of the variables sorted in ascending order) of two datasets as follows:

$r_{S}=1-\frac{6 \sum_{i=1}^{N}\left(R x_{i}-R y_{i}\right)^{2}}{N\left(N^{2}-1\right)}$,

where $N$ is the number of successful numerical simulations analysed. $r_{S}$ is a non-parametric index of statistical dependence between two variables $x$ and $y$ (i.e. here $x=\left[R_{\text {Dif }}, R_{\text {Adv }}, R_{\text {Pro }}, R_{\text {ea }}\right]$ and $y=$ $\left.\left[t_{b}, t_{e}, \mu_{\mathrm{FF}}, \sigma_{\mathrm{FF}}, T_{\text {cte }}, \Delta T, G_{\mathrm{LB}}, \Delta G\right]\right)$ which is based on the corresponding ranked variables $R x$ and $R y$. Ranks are established according to the position of the variables sorted in ascending order. Hence, Spearman's coefficient $r_{S}$ presents the advantage of detecting nonlinear dependencies on the single condition that they follow monotonic tendencies. Positive and negative good correlations between the two datasets compared are then revealed by $r_{S}$ values tending towards 1 and -1 , respectively. Spearman's coefficients close to 0 mean either a minor and negligible dependence or a non-monotonic tendency within the range of $x$ values analysed. These non-linear correlation coefficients $r_{S}$ are therefore very useful as they can be used to identify the main monotonic intercorrelations between the contributions of the processes and the quantified features of the inverted $T_{\text {peak }}$ profiles.

Tables 3 and 4 gather the different corresponding Spearman's correlation coefficients $r_{S}$ for the occurrences in time and for the fitting function parameters, respectively. As evidenced in Fig. 6(a), heat advection constitutes the only thermal process for which the contribution is particularly restricted in an intracontinental context. $R_{\text {Adv }}$ generally stays under 0.4 , whereas $R_{\text {Dif }}$ and $R_{\text {Pro }}$ mostly range between 0.05 and 0.95 . Consequently, heat advection is always a minor thermal process and the Spearman's correlations calculated for $R_{\mathrm{Dif}}, R_{\mathrm{Adv}}$ and $R_{\mathrm{Pro}}$ are all influenced by this restriction. Therefore, $R_{\text {Dif }}$ and $R_{\text {Pro }}$ related coefficients $r_{S}$ express the control over these two poles much more than a global influence. Thus they tend to be of the same absolute order of magnitude but their sign indicates opposite trends (negative and positive; see Tables 3 and 4). On the contrary, coefficients for the $R_{\text {ea }}$ ratio can be safely interpreted for the intracontinental context as both converted processes (erosion and accretion) are considered to be independent from thermal processes in our model.

\section{RESULTS}

Any inverted $T_{\text {peak }}$ profile can be accurately examined using the six analytical parameters included in the fitting function $T_{\mathrm{FF}}$ (i.e. $\left[\mu_{\mathrm{FF}}, \sigma_{\mathrm{FF}}, T_{\mathrm{cte}}, \Delta T, G_{\mathrm{LB}}, \Delta G\right]$; see Section 5.1). Furthermore, any inversion can be characterized by its occurrence in time, starting at time $t_{b}$ and ending at time $t_{e}$. The time of the end of the inversion is limited to $15 \mathrm{Myr}$, which corresponds to the duration of the simulations. The mean value and standard deviation of each one of these six parameters calculated over the duration of each inversion are used to describe their main tendency and their variability in time, respectively. As an example, the combinations of analytical parameters (mean value $\pm 1 \sigma$ ) corresponding to the five illustrative cases displayed in Fig. 6 are detailed in Table 2.

\subsection{Occurrences of peak temperature inversions}

Fig. 7(a) displays the percentage of experiments presenting, at some point, a $T_{\text {peak }}$ inversion (according to the three criteria of selection presented in Section 4.2), as a function of depth $z_{f}$. This percentage increases significantly with depth, from less than 30 per cent close to the surface to more than 80 per cent at $z_{f}=25 \mathrm{~km}$. The number of $T_{\text {peak }}$ inversions preserved throughout time follows the same tendency, reaching $\sim 50$ pe cent at $z_{f}=30 \mathrm{~km}$.

The third criterion (see Section 4.2) that limits the selection of $T_{\text {peak }}$ profiles, constitutes a major limitation. Without this criterion, the percentage of simulations presenting a $T_{\text {peak }}$ inversion would reach almost 100 per cent regardless of the depth $z_{f}$ (Fig. 7a). Only thrust systems dominated by heat diffusion compared to heat advection and shear heating (i.e. $R_{\text {Dif }}>1 / 3$ to $1 / 5$ ) and with fast accretion $\left(R_{\text {ea }} \rightarrow 0\right)$ do not present any $T_{\text {peak }}$ inversion based on the three criteria (Fig. 7b).

Heat advection is linked with the burial of the colder lower block under the hotter upper block. In this case, temperatures within the thrust zone progressively decrease due to the downward heat diffusion. The $T_{\text {peak }}$ of the rocks involved within the thrust zone thus corresponds to their initial thermal state which consequently is also always higher than the progressively heated lower block. Shear heating and erosion both increase the $T_{\text {peak }}$ within the thrust zone by internal heat production and by the diffusion of heat from the upper block, respectively. At shallower levels, the heating of the lower block from its top is much more restricted due to the surface thermal boundary condition. This results in a much higher control of heat diffusion $\left(R_{\text {Dif }}\right)$ on the occurrence of inverted $T_{\text {peak }}$ profiles. At deeper levels, the limit between the experiments presenting a $T_{\text {peak }}$ inversion based on the three selection criteria, and those that do not, becomes much less clear (Fig. 7b) because the profiles are close to 


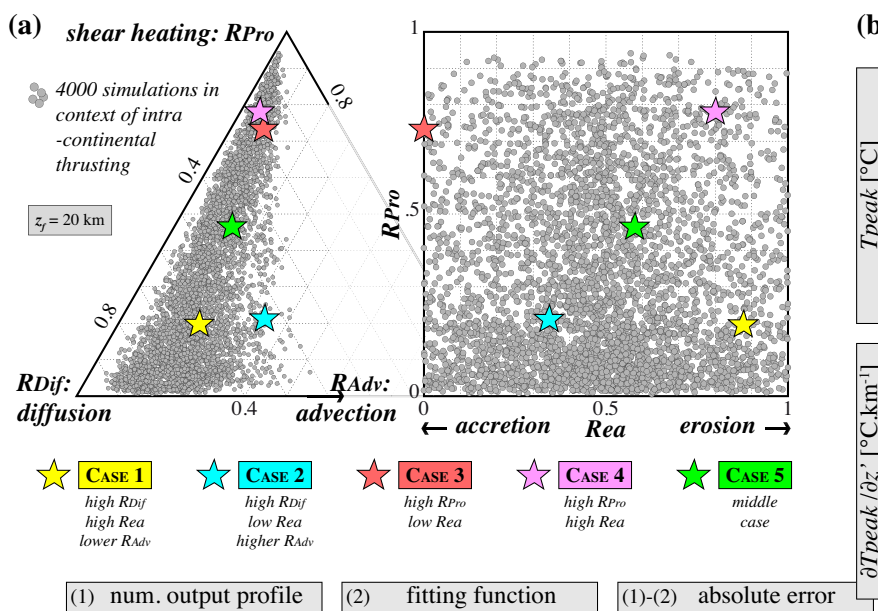

(b) (1) num. output profile (2) fitting function (1)-(2) absolute error
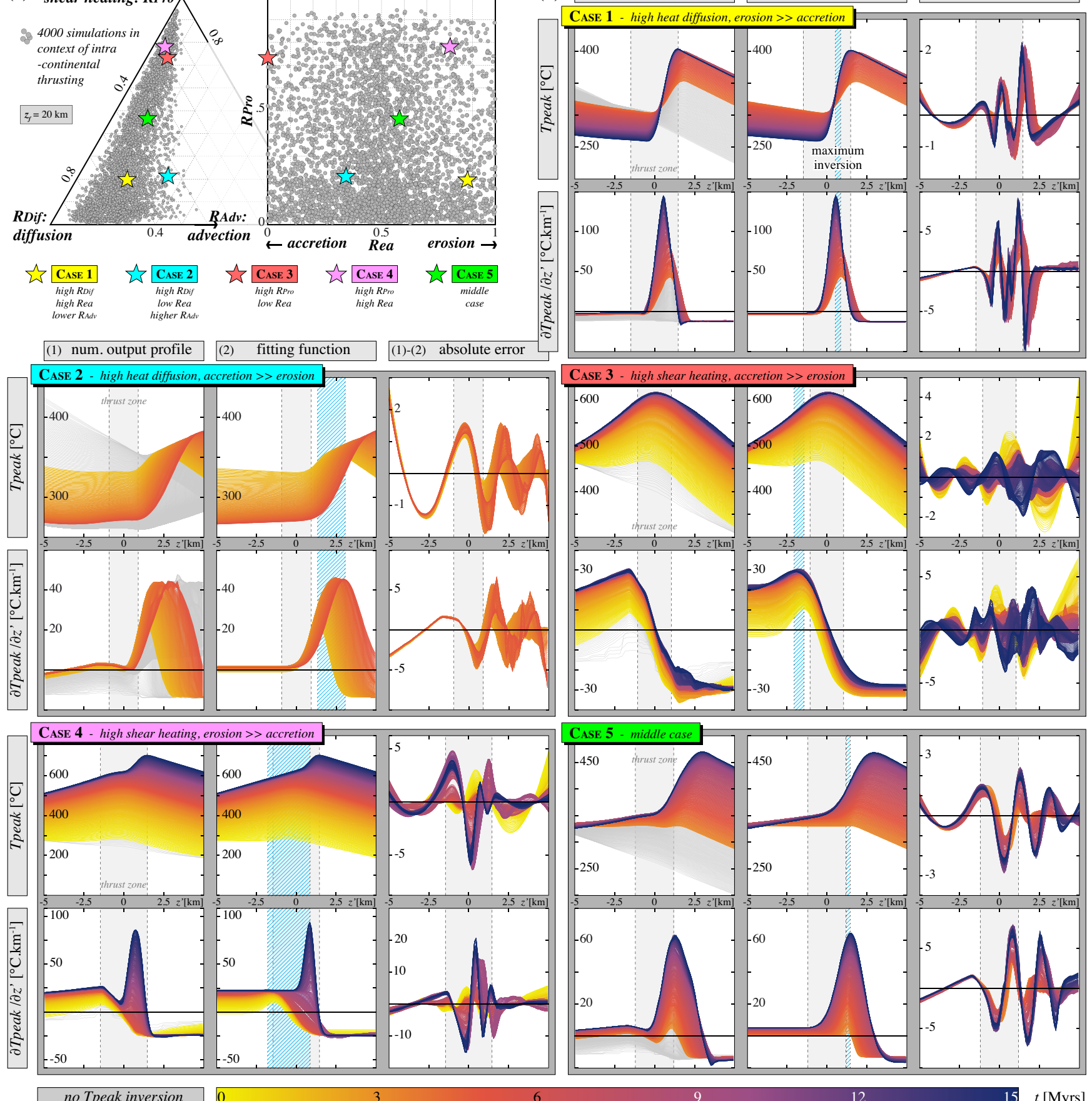

o Tpeak inversion

0

Figure 6. (a) Contributions of the three thermal processes $\left[R_{\mathrm{Dif}}, R_{\mathrm{Adv}}, R_{\mathrm{Pro}}\right]$ (left ternary diagram; following the method described by Duprat-Oualid et al. 2015) and contributions of shear heating, $R_{\text {Pro }}$, compared to the relative importance of erosion in relation to accretion, $R_{\text {ea }}$ (right-hand diagram), for each numerical simulation at depth $z_{f}=20 \mathrm{~km}$. Coloured stars refer to the five cases illustrated in (b). (b) Application of the fitting function for the five cases of numerical simulations selected in order to show the distinct types of $T_{\text {peak }}$ inversion along the $20 \mathrm{~km}$ depth profile. In each case, the numerical output $T_{\text {peak }}$ profiles and their corresponding gradient $\partial T_{\text {peak }} / \partial z^{\prime}$ are presented over time in the left-hand column, at the top and bottom, respectively. Only the selected inverted profiles are highlighted by colours, which correspond to time (while the fine grey curves show the other profiles). These selected profiles are then converted into the general fitting function $T_{\mathrm{FF}}$ (middle column). The vertical hatched light blue zones indicate the $z^{\prime}$ domain where the intensity of the inversion is the highest over time. Diagrams in the right-hand column show the associated absolute errors between the numerical output data and the analytical fitting function conversion: the error diagrams on top correspond to $T_{\text {peak }}\left(z^{\prime}\right)-T_{\mathrm{FF}}\left(z^{\prime}\right)$, in ${ }^{\circ} \mathrm{C}$; the error diagrams at the bottom correspond to $\partial T_{\text {peak }} / \partial z^{\prime}\left(z^{\prime}\right)-\partial T_{\mathrm{FF}} / \partial z^{\prime}\left(z^{\prime}\right)$, in ${ }^{\circ} \mathrm{C} \mathrm{km}{ }^{-1}$. The interpolation of temperatures from the grid nodes to the particles results in non-smooth $T_{\text {peak }}$ profiles, responsible for the regularly fluctuating errors along the $z^{\prime}$-axis. The average and standard deviation values for each one of the six parameters involved in the analytical approximation for the five examples are displayed in Table 2 . 
Table 3. Spearman's rank correlations quantifying the global sensitivity of the beginning $\left(t_{b}\right)$ and ending $\left(t_{e}\right)$ times of the $T_{\text {peak }}$ inversions to the contributions of the thermal processes of heat diffusion $\left(R_{\text {Dif }}\right)$, heat advection $\left(R_{\text {Adv }}\right)$ and shear heating $\left(R_{\text {Pro }}\right)$, and to the relative importance of erosion and accretion $\left(R_{\mathrm{ea}}\right)$. Results are displayed for three profiles centred at $z_{f}=10$, 20 and $30 \mathrm{~km}$, respectively. In the lower part of the table, Spearman's rank correlations are established by considering the numerical input parametric combinations which only lead to a minor influence of shear heating.

\begin{tabular}{|c|c|c|c|c|c|}
\hline & & $R_{\text {Dif }}$ & $R_{\mathrm{Adv}}$ & $R_{\text {Pro }}$ & $R_{\mathrm{ea}}$ \\
\hline \multirow[t]{3}{*}{$t_{b}$} & $z_{f}=10 \mathrm{~km}$ & 0.87 & 0.48 & -0.82 & 0.39 \\
\hline & $z_{f}=20 \mathrm{~km}$ & 0.76 & 0.31 & -0.66 & 0.18 \\
\hline & $z_{f}=30 \mathrm{~km}$ & 0.74 & 0.28 & -0.63 & 0.07 \\
\hline \multirow[t]{3}{*}{$t_{e}$} & $z_{f}=10 \mathrm{~km}$ & -0.13 & -0.16 & 0.15 & 0.12 \\
\hline & $z_{f}=20 \mathrm{~km}$ & -0.32 & -0.44 & 0.39 & 0.37 \\
\hline & $z_{f}=30 \mathrm{~km}$ & -0.23 & -0.27 & 0.26 & 0.44 \\
\hline \multicolumn{6}{|c|}{ Minor shear heating: $R_{\text {Pro }}<R_{\text {Dif }}$ and $R_{\text {Pro }}<R_{\mathrm{Adv}}$} \\
\hline \multirow[t]{3}{*}{$t_{b}$} & $z_{f}=10 \mathrm{~km}$ & 0.69 & -0.64 & -0.43 & -0.22 \\
\hline & $z_{f}=20 \mathrm{~km}$ & 0.69 & -0.61 & -0.39 & 0.14 \\
\hline & $z_{f}=30 \mathrm{~km}$ & 0.67 & -0.57 & -0.38 & 0.03 \\
\hline \multirow[t]{3}{*}{$t_{e}$} & $z_{f}=10 \mathrm{~km}$ & 0.34 & -0.35 & -0.17 & 0.48 \\
\hline & $z_{f}=20 \mathrm{~km}$ & 0.37 & -0.37 & -0.17 & 0.82 \\
\hline & $z_{f}=30 \mathrm{~km}$ & 0.18 & 0.17 & -0.08 & 0.75 \\
\hline
\end{tabular}

the bottom of the upper block (i.e. $z_{f} \sim z_{m}$ ). When the thrust system corresponds to an accretionary domain $\left(R_{\text {ea }} \rightarrow 0\right)$, heat is laterally transferred from the active thrust zone toward the upper block. Hence, high accretion velocities $\left(R_{\text {ea }}<0.7\right)$ allow for a thermal balance between the active thrust zone and its lower block versus heat advection and erosion. However, in the range of velocities between 0 and $2.5 \mathrm{~mm} \mathrm{yr}^{-1}$ as considered here, accretion remains of minor importance when shear heating dominates the thermal budget of the active thrust zone (i.e. when $R_{\text {Pro }}>0.5$ ).

Except at shallow depths, $T_{\text {peak }}$ inversions may occur around the thrust zone for all process contribution configurations, even for relatively high heat diffusion $\left(R_{\text {Dif }} \rightarrow 1\right)$ and fast accretion $\left(R_{\text {ea }} \rightarrow 0\right.$; Fig. 7b). Consequently, no single process is responsible for the development of an inverted metamorphic zonation in the vicinity of intracontinental thrust zones. However, depending on the degree of implication of the different processes, the metamorphic thermal signature will be much more contrasted (e.g. Figs 1c and 6). By analysing how a $T_{\text {peak }}$ inversion is expressed (timing, intensity, location and width of the inversion, $T_{\text {peak }}$ trends in both blocks), we can go further to distinguish the controlling processes in the different contexts.
For example, Case 5 illustrated in Fig. 6 shows a late and lasting $T_{\text {peak }}$ inversion similar to Case 1 in terms of timing. However, their metamorphic thermal signatures are drastically different. First, the inversion is much more intense ( $\sim$ two times higher) in Case 1 than in Case 5. Second, the inversion is located inside the thrust zone in Case 1 whereas it straddles its upper limit in Case 5. Finally, the $T_{\text {peak }}$ within the lower block regularly decreases in Case 1 contrary to Case 5. Therefore, it becomes crucial to understand how the variability in the metamorphic thermal signature is expressed, especially because metamorphic records in nature constitute the only accessible witnesses of the thermal phenomena occurring at depth. With this aim in mind, we propose below to analyse the temporal, spatial and thermal features of inverted $T_{\text {peak }}$ profiles resulting from our numerical experiments so as to link them to particular processes.

\subsection{Characterization of $T_{\text {peak }}$ inversions}

In order to characterize $T_{\text {peak }}$ inversions, we specifically focus on profiles centred at $z_{f}=20 \mathrm{~km}$ because they are far enough from both the surface (i.e. the upper thermal boundary) and the base $z_{m}$ of the continental crust. Furthermore, nearly 80 per cent of the performed simulations show a $T_{\text {peak }}$ inversion along the $20 \mathrm{~km}$ depth profiles (Fig. 4a), which can be used to broadly sample the set of features for the inverted $T_{\text {peak }}$ profiles.

In the following, we provide an overview of our results as a guide for the interpretation of IMS. We highlight the major impacts of the different processes on the inverted $T_{\text {peak }}$ signatures. A full report presenting a detailed description of each temporal, spatial or thermal feature of the inverted $T_{\text {peak }}$ profiles is provided in Appendix B. The occurrences of $T_{\text {peak }}$ inversions in time (i.e. $t_{b}$ and $t_{e}$ ) at different depths are presented in Appendix B1 and Fig. B1. Mean values and standard deviations over the duration of the inversions of the two spatial parameters $\left(\mu_{\mathrm{FF}}\right.$ and $\left.\sigma_{\mathrm{FF}}\right)$ are displayed in Fig. B2 and developed in Appendix B2. Similarly, the four thermal features ( $T_{\text {cte }}, \Delta T, G_{\mathrm{LB}}$ and $\Delta G$ ) are given in Appendix B3 and Fig. B3. In addition, the mean values for the six fitting function parameters $\left(\mu_{\mathrm{FF}}, \sigma_{\mathrm{FF}}, T_{\text {cte }}, \Delta T, G_{\mathrm{LB}}\right.$ and $\Delta G$ ) are compared between each other in Appendix $\mathrm{C}$ in order to clearly point out the first order interdependencies (Fig. C1).

Our results show that, at the first order, the competition between the two heat diffusion $\left(R_{\text {Dif }}\right)$ and shear heating $\left(R_{\text {Pro }}\right)$ end-members appears to have a greater influence on the evolution of all $T_{\text {peak }}$ inversion features in an intracontinental context. If the other processes turn out to be important, their influence depends on the dominance of shear heating with regards to heat diffusion. Consequently,

Table 4. Spearman's rank correlations quantifying the global sensitivity of the output fitting function parameters $\left[\mu_{\mathrm{FF}}, \sigma_{\mathrm{FF}}, T_{\mathrm{cte}}, \Delta T, G_{\mathrm{LB}}, \Delta G\right]$ to the thermal processes contributions of heat diffusion $\left(R_{\mathrm{Dif}}\right)$, heat advection $\left(R_{\mathrm{Adv}}\right)$ and shear heating $\left(R_{\mathrm{Pro}}\right)$, and to the relative importance of erosion and accretion $\left(R_{\mathrm{ea}}\right)$. In order to take into account the variability of the output analytical parameters over the duration of the $T_{\text {peak }}$ inversions, a set of 10000 Spearman's coefficients is calculated with normally distributed random values on the basis of the mean and the standard deviation characterizing each analytical parameter. Results are presented with the mean $r_{S}$ associated with its standard deviation $( \pm 1 \sigma)$.

\begin{tabular}{|c|c|c|c|c|c|}
\hline & & $R_{\text {Dif }}$ & $R_{\mathrm{Adv}}$ & $R_{\text {Pro }}$ & $R_{\mathrm{ea}}$ \\
\hline \multirow[t]{3}{*}{$\mu_{\mathrm{FF}}$} & All & $0.35 \pm 0.01$ & $0.46 \pm 0.01$ & $-0.41 \pm 0.01$ & $-0.07 \pm 0.01$ \\
\hline & $<0$ & $-0.16 \pm 0.03$ & $-0.35 \pm 0.03$ & $0.24 \pm 0.03$ & $0.21 \pm 0.04$ \\
\hline & $>0$ & $-0.01 \pm 0.02$ & $0.30 \pm 0.01$ & $-0.09 \pm 0.02$ & $-0.40 \pm 0.01$ \\
\hline$\sigma_{\mathrm{FF}}$ & & $-0.29 \pm 0.01$ & $-0.18 \pm 0.01$ & $0.27 \pm 0.01$ & $-0.31 \pm 0.01$ \\
\hline$T_{\text {cte }}$ & & $-0.60 \pm 0.00$ & $-0.49 \pm 0.00$ & $0.61 \pm 0.00$ & $0.04 \pm 0.00$ \\
\hline$\Delta T$ & & $0.53 \pm 0.01$ & $0.46 \pm 0.01$ & $-0.57 \pm 0.01$ & $0.29 \pm 0.01$ \\
\hline$G_{\mathrm{LB}}$ & & $-0.92 \pm 0.00$ & $-0.57 \pm 0.00$ & $0.89 \pm 0.00$ & $-0.12 \pm 0.00$ \\
\hline$\Delta G$ & & $0.74 \pm 0.01$ & $0.45 \pm 0.01$ & $-0.69 \pm 0.01$ & $0.06 \pm 0.01$ \\
\hline
\end{tabular}



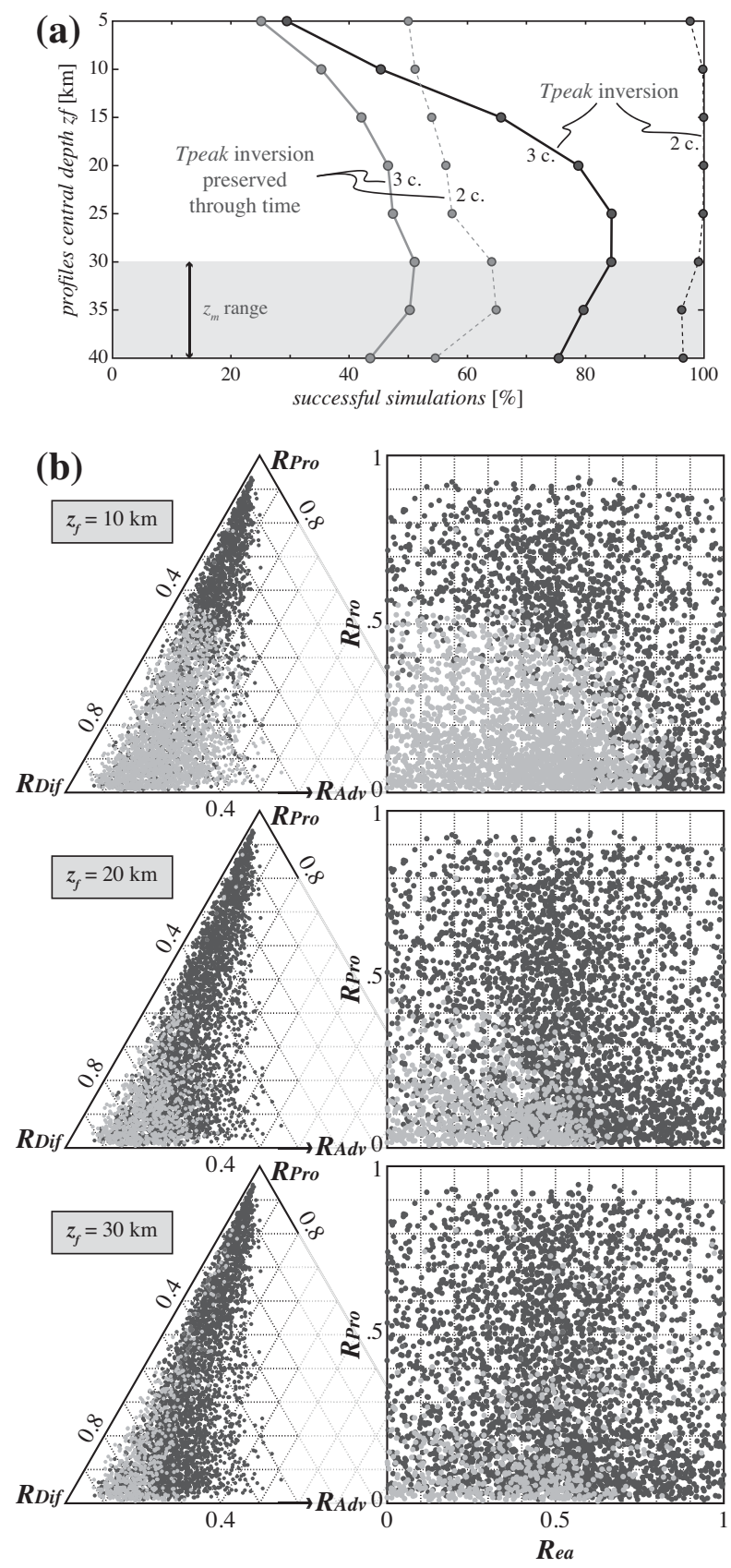

Figure 7. (a) Occurrences (in \%) of $T_{\text {peak }}$ inversion (in black) and $T_{\text {peak }}$ inversion preserved during the whole simulation (i.e. at least 15 Myr; in grey) as a function of the depth $z_{f}$. Bold lines illustrate the results for $T_{\text {peak }}$ profiles that fulfil the three selection criteria (3c.; see Section 4.2). Thin dashed lines are related to inverted $T_{\text {peak }}$ profiles that only fulfil the first two conditions (2c.; see text). The light grey zone corresponds to the range of $z_{m}$ depths. (b) Occurrence (light grey dots) and absence (dark grey dots) of $T_{\text {peak }}$ inversion, according to the three selection criteria, at different profile depths $\left(z_{\mathrm{f}}=10,20\right.$ and $\left.30 \mathrm{~km}\right)$ shown with respect to the contributions of the processes (as for Fig. 6a).

inverted $T_{\text {peak }}$ signatures can be simply treated as the balance between shear heating, accretion and erosion, and can therefore be analysed in $\left[R_{\text {ea }}, R_{\text {Pro }}\right]$ diagrams.

In each panel shown in Fig. 8, the main tendencies (mean values) and variabilities in time (standard deviations) are presented for each characteristic of the $T_{\text {peak }}$ inversion in time ( $t_{b}$ and $t_{e}$; Figs $8 \mathrm{a}$ and b), in space ( $\mu_{\mathrm{FF}}$ and $\sigma_{\mathrm{FF}}$; Figs $8 \mathrm{c}$ and $\mathrm{d}$ ) as well as in terms of the $T_{\text {peak }}$ trends of the inversion zone ( $T_{\text {cte }}$ and $\Delta T$; Figs $8 \mathrm{e}$ and $\mathrm{f}$ ) and outwards ( $G_{\mathrm{LB}}$ and $\Delta G$; Figs $8 \mathrm{~g}$ and h). Fig. 8 illustrates a global overview that reports the critical processes, or combinations of processes, that control the evolution of the inverted peak temperature signature.

Fig. 8 distinguishes four major combinations of process contributions controlling the different characteristics of the $T_{\text {peak }}$ inversion. Depending on the contributions of the processes, that is the location in the four quarters of the $\left[R_{\mathrm{ea}} ; R_{\text {Pro }}\right]$ diagram (Fig. 6a), the inverted $T_{\text {peak }}$ profiles highly differ as illustrated by Cases 1 to 4 in Fig. 6(b).

\subsubsection{Low $R_{\text {Pro }}-$ high $R_{\text {ea }}($ Case 1)}

When shear heating is a minor thermal process $\left(R_{\text {Pro }}<R_{\text {Dif }}\right.$, i.e. $R_{\text {Pro }}<\sim 0.5$ ), advective processes control the thermal perturbation associated with the activity of the thrust. In such low $R_{\text {Pro }}$ conditions, erosion and accretion control two different styles of $T_{\text {peak }}$ inversions. Relatively high erosion velocities $\left(R_{\text {ea }} \rightarrow 1\right)$ lead to a fast exhumation of the upper block. Therefore, thrusting by rocks that were originally hotter contributes to an increase in the $T_{\text {peak }}$ values in the upper block (i.e. $z^{\prime}>0$ ). The $T_{\text {peak }}$ inversion is then governed by the temperature contrast between the upper and lower blocks, establishing a long-term inversion $\left(t_{e} \rightarrow \infty\right.$; Fig. 8b). This $T_{\text {peak }}$ inversion is centred inside the thrust zone $\left(\mu_{\mathrm{FF}} \rightarrow 0\right.$ associated with a low standard deviation $\sigma \rightarrow 0$; Fig. 8c) and is found over a very limited extent $\left(\sigma_{\mathrm{FF}}<0.5 \mathrm{~km}\right.$, associated with a low standard deviation $\rightarrow 0$; Fig. 8 d).

In addition, $T_{\text {cte }}$ is governed by the initial thermal field of the lower block and the amount of heat diffused from the upper block. Consequently, $T_{\text {cte }}$ is restricted to cold values (e.g. $<400{ }^{\circ} \mathrm{C}$ at $z_{f}=20 \mathrm{~km}$; Fig. 8e) and the characteristic basal gradient $G_{\mathrm{LB}}$ remains negative (Fig. $8 \mathrm{~g}$ ). Towards higher shear heating contributions $\left(R_{\text {Pro }} \rightarrow 0.5\right), T_{\text {cte }}$ tends to reach $\sim 500{ }^{\circ} \mathrm{C}$ and $G_{\mathrm{LB}}$ also increases until it attains positive values. In low $R_{\text {Pro }}$-high $R_{\text {ea }}$ conditions, $T_{\text {peak }}$ on either side of the thrust is thus controlled by the initial thermal field in each block. Therefore, the difference in the $T_{\text {peak }}$ gradient $\Delta G$ remains close to 0 (Fig. $8 \mathrm{~h}$ ). The contrast $\Delta T$ in $T_{\text {peak }}$ increases with time, and is marked by $\Delta T$ values ranging between 100 and $200 \pm 40^{\circ} \mathrm{C}$ (Fig. 8f) until it reaches a steady state.

\subsubsection{Low $R_{\text {Pro }}-$ low $R_{\text {ea }}($ Case 2)}

When accretion predominates over erosion $\left(R_{\text {ea }}<0.5\right)$, the thermal features $\left[T_{\text {cte }}, \Delta T, G_{\mathrm{LB}}, \Delta G\right]$ are still linked to the initial thermal state on both sides of the inversion zone such that they are quite similar to the resulting values at higher $R_{\text {ea }}$ (Figs $8 \mathrm{e}-\mathrm{h}$ ). A small decrease in $\Delta T$ may be observed because the $T_{\text {peak }}$ values above the inversion zone are not necessarily linked to the deeper domain (due to lower erosion). If the thermal features are similar, irrespective of the $R_{\text {ea }}$ value, the inversion zone moves to the upper side of the last active thrust when the accretion velocity $a$ increases ( $\mu_{\mathrm{FF}}$ reaches $\sim 1$ to $2 \mathrm{~km}$ above the centre of the active thrust; Fig. $8 \mathrm{c}$ ). The lateral transfer of the thrust due to accretion results in a short duration of the inversion in the vicinity of the active thrust, generally ending before $10 \mathrm{Myr}$ of convergence (at $z_{f}=20 \mathrm{~km}$; Fig. $8 \mathrm{~b}$ ).

\subsubsection{High $R_{\text {Pro }}-$ low $R_{\text {ea }}($ Case 3)}

When shear heating dominates the thermal budget around the thrust $\left(R_{\text {Pro }}>0.5\right)$, a drastic change occurs for all features (Fig. 8, upper part of the diagrams). At high accretion or low erosion $\left(R_{\text {ea }} \rightarrow 0\right)$, a sharp switch occurs at $R_{\text {Pro }}=0.5$ due to the intense inner heat 
(a) beginning : $t b$

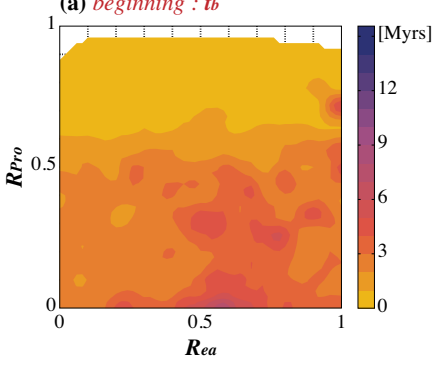

(b) ending : te

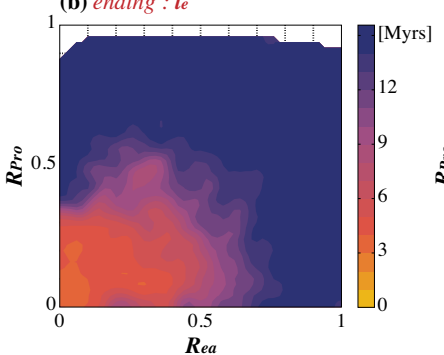

(c) max. inversion location : $\boldsymbol{\mu}_{\mathrm{FF}}$

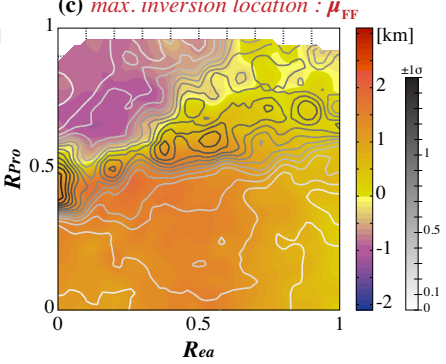

(d) inversion extent : $\sigma_{\mathrm{FF}}$

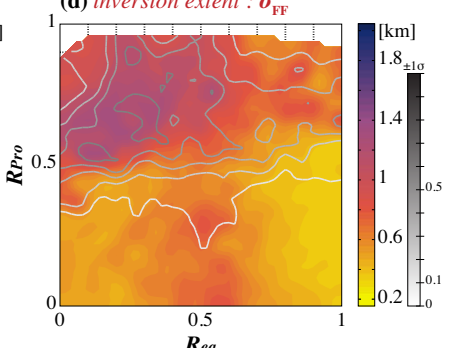

(e) basal Tpeak : Tcte

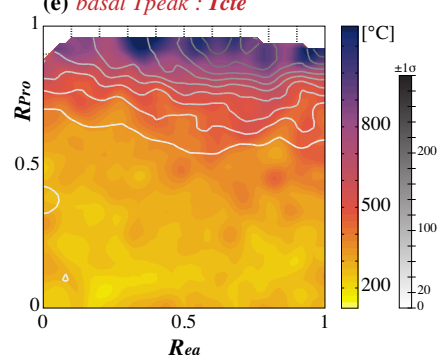

(f) Tpeak difference : $\boldsymbol{\Delta} \boldsymbol{T}$

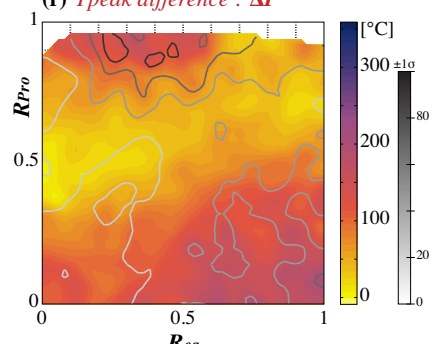

(g) basal Tpeak gradient : $\boldsymbol{G}_{\mathrm{LB}}$

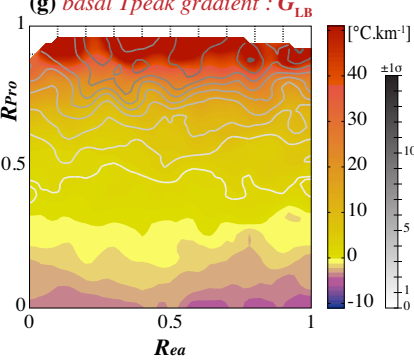

(h) Tpeak gradient difference : $\Delta \boldsymbol{G}$

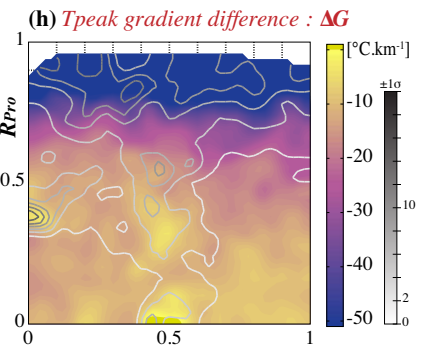

Rea

Figure 8. Compilation of the eight features calculated to characterize the $T_{\text {peak }}$ inversions occurring at $z_{f}=20 \mathrm{~km}$ : (a) beginning time $t_{b}$, (b) ending time $t_{e}$, (c) location of the maximum inversion $\mu_{\mathrm{FF}}$, (d) extent of the inversion $\sigma_{\mathrm{FF}}$, (e) basal peak temperature $T_{\text {cte }}$, (f) peak temperature difference $\Delta T$, (g) basal peak temperature gradient $G_{\mathrm{LB}}$ and $(\mathrm{h})$ peak temperature gradient difference $\Delta G$. All of these features are presented in the $\left[R_{\mathrm{Pro}}, R_{\mathrm{ea}}\right]$ field diagram. In each diagram, the background coloured map corresponds to the resulting mean values (interpolated from Figs B1b, B2b and B3b). In diagrams (c) to (h), the different grey lines correspond to the mean variations in the fitting function parameter values over the inversion duration (after Figs B2d and B3d). Hence, the darker is the line, the larger is the standard deviation from the value plotted in background colour.

production. The maximum peak temperatures recorded along the profiles are not located in the upper block but inside the thrust zone. Consequently, the maximum inversion sets in the lower part of the thrust zone $\left(\mu_{\mathrm{FF}}<0\right.$; Fig. 8c). This transition between low and high shear heating contribution is marked by the instability of the inversion in space as evidenced by the high standard deviation values for $\mu_{\mathrm{FF}}$ (Fig. 8c). The fast heat production leads to an early beginning of inversion $\left(t_{b}<2\right.$ Myr; Fig. 8a). The simultaneous diffusion on both sides, particularly towards the lower colder block, results in a wider inversion zone through time $\left(\sigma_{\mathrm{FF}}>1 \mathrm{~km}\right.$; Fig. 8d). Progressively, the basal $T_{\text {peak }}$ value ( $T_{\text {cte }}$ ) undergoes a high increase by several hundreds of degrees Celsius (Fig. 8e). A similar evolution is obtained for the basal $T_{\text {peak }}$ gradient $\Delta G$ which reaches several tens of degrees per kilometre (Fig. 8g). The lateral thermal evacuation due to accretion is almost insignificant and demonstrates the possible dominance of shear heating in a continental lithosphere under tectonic stresses. With regards to the upper domain, shear heating may be so powerful that basal cooling due to heat advection along the thrust may be balanced and the initially acquired $T_{\text {peak }}$ values may be exceeded. The characteristic $T_{\text {peak }}$ difference $\Delta T$, which is then established between $T_{\text {cte }}$ and the $T_{\text {peak }}$ state on top of the thrust zone, is similar to values at low $R_{\text {Pro }}$ (i.e. ranging between 100 and $200{ }^{\circ} \mathrm{C}$; Fig. 8f). The $T_{\text {peak }}$ gradient in the upper block is notably intensified. Consequently, $T_{\text {peak }}$ gradients in both blocks undergo high opposite changes leading to a contrast $\Delta G$ that is much higher than $50{ }^{\circ} \mathrm{C} \mathrm{km}^{-1}$ in absolute values when $R_{\text {Pro }} \rightarrow 1$ (Fig. $8 \mathrm{~h}$ ). If shear heating continues to dominate the thermal budget (i.e. $R_{\text {Pro }}>0.5$ ), the inversion may be preserved without any time limitation $\left(t_{e} \rightarrow \infty\right.$; Fig. 8b).

\subsubsection{High $R_{\text {Pro }}-$ high $R_{\text {ea }}($ Case 4)}

Under an intense contribution of shear heating $\left(R_{\text {Pro }}>0.5\right)$, the increasing velocity of the upper block allowed by high surface de- nudation $\left(R_{\text {ea }} \rightarrow 1\right.$ ) leads to significant changes in the $T_{\text {peak }}$ signature. If shear heating dominates the thermal field at earlier stages, the advection of hot material on top has an impact on the long-term scheme. The $T_{\text {peak }}$ inversion is first established in the lower part of the thrust system as previously shown, but progressively switches to the upper part due to the dominance of erosion. The mean location $\mu_{\mathrm{FF}}$ of the maximum inversion moves closer to $z^{\prime}=0$ and this trend is then associated with a high standard deviation between 0.5 and $1 \mathrm{~km}$ (Fig. 8c). The extent of inversion $\sigma_{\mathrm{FF}}$ is limited to $1 \mathrm{~km}$ or less (Fig. 8d) associated with a significant decrease in the characteristic $T_{\text {peak }}$ difference $\Delta T$ values lower than $100{ }^{\circ} \mathrm{C}$ (Fig. 8f). In comparison, the other parameters remain indifferent to the $R_{\text {ea }}$ variation.

\section{DISCUSSION}

This study can be used to address the meaning of inverted peak temperature signatures. It is based on a simplified view of thrust systems, which considers all parameters (and processes) as constants. Nevertheless, the importance of some parameters revealed here (such as the viscosity as well as the erosion and accretion velocities) questions the influence of their variability in time and space, which needs to be discussed.

\subsection{Variability in the rheology of the thrust and shear heating contribution}

The variability in the $T_{\text {peak }}$ inversions around the thrust zone appears to be mainly controlled by the balance between the contributions of shear heating $\left(R_{\text {Pro }}\right)$ and heat diffusion $\left(R_{\text {Dif }}\right)$. This balance depends on the effective viscosity of the rocks involved in the shear zone, which corresponds, by far, to the most important parameter (Table A1). However, the mechanical behaviour of a thrust is never constant in either time or space and highly depends on the surround- 
ing conditions (e.g. $P, T$, strain rate). Brittle behaviour depends on the pressure and is well known mainly through laboratory experiments (Paterson \& Wong 2005). On the contrary, ductile behaviour is much less constrained and the effective viscosity is governed by complex interrelations between the temperature, nature of the rocks, deformation and evolution of the mechanical anisotropies in time (Poirier 1980). The high variability in the viscosity $\eta$ (over several orders of magnitude) then constitutes an issue that fuels discussions about the strength of the lithosphere (e.g. Ranalli \& Murphy 1987; Burov \& Watts 2006; Bürgmann \& Dresen 2008; Schmalholz et al. 2009), as well as the importance of shear heating depending on the tectonic context (e.g. Bird 1978; Barton \& England 1979; Lachenbruch \& Sass 1980, 1992; Peacock 1992; Leloup \& Kienast 1993; Stüwe 1998; Leloup et al. 1999; Camacho et al. 2001; Nabelek et al. 2001, 2010; Hartz \& Podladchikov 2008; Duprat-Oualid et al. 2013; Kidder et al. 2013; Nábělek \& Nábělek 2014). In turn, several studies have also pointed out the importance of shear heating on the evolution of the rheological behaviour of crustal-scale shear zones (e.g. Regenauer-Lieb \& Yuen 1998; Burg \& Schmalholz 2008; Duretz et al. 2014; Jaquet \& Schmalholz 2017) and, more generally, on the mechanical strength of the lithosphere (e.g. Scholz 1980; Burg \& Gerya 2005; Regenauer-Lieb et al. 2006, 2008; Burg \& Schmalholz 2008; Hartz \& Podladchikov 2008). If the viscosity decreases with an increase in temperature, the shear heating contribution $\left(R_{\text {Pro }}\right)$ also decreases accordingly, and this can drastically impact the signature of peak temperature inversions.

Hence, as an example, if the thermal budget of a thrust system is initially dominated by shear heating $\left(R_{\text {Pro }}>0.3-0.5\right)$ at a given depth $z_{f}$, a $T_{\text {peak }}$ inversion develops early $\left(t_{b}<3\right.$ Myr; Fig. 8a) below the thrust zone $\left(\mu_{\mathrm{FF}}<0\right.$; Fig. 8c). This inversion is first characterized by a rapid (after some Myr) increase in the temperatures up to $\sim 100{ }^{\circ} \mathrm{C}$ in the vicinity of the thrust (e.g. Reitan 1968a; Graham \& England 1976; Scholz 1979; Brun \& Cobbold 1980; Brewer 1981; Pavlis 1986; Duretz et al. 2014; Fig. 8e). The induced drop in viscosity (among other processes such as grain size reduction or fluid circulation) leads to a decrease in shear heating production. Over the long term, the inverted metamorphic sequence then instead develops thermal features corresponding to low- $R_{\text {Pro }}$ thrust systems (i.e. the inversion is more centred in the thrust zone with a lower $T_{\text {peak }}$ in the lower block; Figs $8 \mathrm{c}$ and e). Due to the increasing control by diffusion and advection, the thrust zone temperature also decreases. However, the upper block records the early high temperature metamorphic stage while the downgoing lower block records the last heating stage. This scenario may explain the diachronous thermal histories observed in stacked metamorphic units associated with unusual high $T_{\text {peak }}$ values within the upper block.

The contribution of shear heating is not only sensitive to $\eta$ but also depends on the kinematic scheme (i.e. $V$ and $h$ in eq. 3 ). In the ranges of values tested here for the intracontinental context (between 1 and $3 \mathrm{~cm} \mathrm{yr}^{-1}$ ), the velocity $V$ constitutes the second most influential parameter (Table A1). High convergence velocity $V$ mainly favours the shear heating contribution but also heat advection. With respect to other contexts, the variability in the kinematic parameters may intensely influence the evolution of the thermal field near the shear zone.

\subsection{Erosion and accretion}

Because erosion and/or accretion are often invoked to explain $T_{\text {peak }}$ inversions in the upper block (e.g. Royden 1993; Huerta et al. 1998; Herman et al. 2010; Kidder et al. 2013), both of these processes need to be considered. Considering that shear heating dominates the thermal budget at the thrusting onset, the first $T_{\text {peak }}$ inversion remains dominated by shear heating which quickly and intensively impacts on the local thermal field.

As erosion drives the exhumation of deeper and hotter rocks in the hanging-wall block, the induced increase in temperature (via the 'hot iron' effect) limits the relative impact of shear heating in the footwall block. The $T_{\text {peak }}$ profile in the upper block attests to this exhumation of previously hot and deep rocks, which were possibly also affected by shear heating during thrusting. This might increase the difference in $T_{\text {peak }}$ values between the two sides of the inversion zone (i.e. $\Delta T$; Fig. 8 f). Conversely, the accretion process results in the stacking of rocks impacted by shear heating within the successive active thrust zones. The $T_{\text {peak }}$ inversion is consequently located in the lower part of the upper block $\left(\mu_{\mathrm{FF}}>0\right.$; Fig. $\left.8 \mathrm{c}\right)$. When accretion is high compared to erosion $\left(R_{\text {ea }} \rightarrow 0\right)$, the peak temperature inversion is rapidly transferred far away in a lateral direction and disappears from the active thrust (low $t_{e}$; Fig. 8b).

In this study, erosion and accretion are introduced in the simplest way as end-member configurations: continuous and constant surface denudation of the upper block for the first configuration, and continuous and constant horizontal accretion along the whole thrust zone in the intracontinental domain (i.e. above the depth $z_{m}$ ) for the second configuration. However, in reality, erosion and accretion are much more complex and lead to various possible kinematic schemes.

On the one hand, surface denudation results from the action of different erosive processes (e.g. hillslope and fluvial processes, landslides, rain and wind abrasion) on the topography, which in turn interacts with regional climatic conditions. The choice of a surface evolution model depends on different aspects such as the dimension of the problem (e.g. 2-D or 3-D) or river dynamics (e.g. Whipple $\&$ Tucker 2002), but mostly on the dominant processes acting on that surface. In general, orogenic fronts show steeper relief where erosion is more intense (e.g. Tucker \& Slingerland 1994; Tucker \& Bras 2000). On the other hand, while accretion is often modelled as a continuous transfer (e.g. Huerta et al. 1996, 1998; Bollinger et al. 2006; Kidder et al. 2013; this study), it may seem inappropriate to compare this scheme in detail with observations in thrusts systems. However, field data may match with continuous accretion through ductile shear zones (e.g. Mottram et al. 2014), but accretion is much more commonly associated with an episodic phenomenon leading to duplex structures built by successive shear zones both in space and time (e.g. Mattauer 1986; Srivastava \& Mitra 1994; van Gool $\&$ Cawood 1994). As a result, the way our numerical model is run helps to outline the influences of each process on the possible peak temperature inversion but cannot provide precise indications concerning either erosion or accretion in comparison with field data.

\subsection{Depth and time associated with the peak temperature profiles}

Only an intense shear heating contribution preserved through time can ensure a synchronous inversion of the $T_{\text {peak }}$ profiles. Otherwise, the peak temperatures reached by the two sides of the inversion zone occur at different times (e.g. all configurations shown in Fig. 1a result in diachronous peak temperature profiles as shown in Fig. 1b). The lower side (including the lower block) experiences the prograde event and part of it may be accreted in the upper block. In this case, the closer are the accreted units to the active thrust, the younger are the ages associated with the peak temperatures. The upper part 
of the inversion zone then shows the oldest $T_{\text {peak }}$ value as well as the deepest conditions if the erosion is significant. Abnormally high $T_{\text {peak }}$ values recorded in the upper part of the inversion profile can only result from intense shear heating $\left(R_{\text {Pro }}>0.3-0.5\right)$ occurring at the onset of the thrust system activity.

This study shows that first order clues about the processes in play at depth can be inferred from the different main features of the $T_{\text {peak }}$ inversions. In order to better characterize the inversions, it is possible to track both depths (or lithostatic pressures) and ages associated with the $T_{\text {peak }}$ reached along the same profiles. It would be particularly interesting to analyse natural data that show that the rocks located above the IMS commonly record older and deeper conditions associated with the peak temperatures than the rocks located below (e.g. Metcalfe 1993; Catlos et al. 2001; Yin 2006; Mottram et al. 2014). Following the same methodology as the function of approximation $\left(T_{\mathrm{FF}}\right)$ of inverted $T_{\text {peak }}$ profiles, such depth and time (or age) profiles could also be performed.

\subsection{Applicability to natural IMS}

The function of approximation $T_{\mathrm{FF}}$ developed in this study to fit the inverted $T_{\text {peak }}$ profiles (eq. 13) constitutes a powerful tool to analyse thermal outputs from the models as well as from metamorphic zonations around thrust zones (Fig. 2). This analytical approximation can be used to convert any $T_{\text {peak }}$ estimated from field sampling, as long as the dataset is large enough. Depending on the uncertainty associated with each peak temperature estimate, a set of different $T_{\mathrm{FF}}$ values can then be obtained. Consequently, the six parameters involved in the fitting function $\left[\mu_{\mathrm{FF}}, \sigma_{\mathrm{FF}}, T_{\text {cte }}, \Delta T, G_{\mathrm{LB}}, \Delta G\right]$ will be associated with a range of values that can also be described by their specific averaged values and the corresponding standard deviations.

The function of approximation obtained from natural data (i.e. six parameters characterizing the natural inverted metamorphic sequence) can then be treated in the same way as for the $T_{\text {peak }}$ profiles extracted from our numerical models. Following our methodology, some of the input variables may be fixed specifically to the natural case investigated (e.g. convergence velocity $V$ or thrust dip angle $\theta$ ). Because they have an insignificant role in the contribution of the different processes and the $T_{\text {peak }}$ inversion, some parameters can be also be fixed (Table A1). Nevertheless, some parameters such as thermal conductivity $(k)$, mantle heat flux $(Q)$ and radiogenic heat production $\left(H r_{0}\right.$ and $\left.z_{r}\right)$ should be studied carefully. They control the initial geotherm (eq. 5) and consequently influence the characteristic peak temperature $T_{\text {cte }}$ at the base of the inversion zone when shear heating is not the dominant thermal process (Figs B3a and b).

The rheology of the thrust zone, a critical parameter in the intracontinental context (Section 7.1), needs to be integrated as a variable in the numerical models. In particular, its temperature dependency is likely to result in significant feedback and in diverse peak temperature profiles. Depths (or lithostatic pressures) and times associated with the peak temperatures reached along the profiles extracted from the numerical simulations then could provide valuable constraints for the interpretation of true IMS.

\section{CONCLUSIONS}

This study provides a complete analysis on how peak temperature inversions can be produced depending on the different processes acting during thrusting. This multi-approach study allows to quantitatively link (i) all the parameters defining a thrust (i.e. convergence velocity, dip angle, thrust thickness, thermal properties of rocks, viscosity, erosion velocity and accretion velocity), (ii) the main processes involved during thrusting (heat diffusion, heat advection, shear heating, erosion and accretion) and (iii) the possible features of $T_{\text {peak }}$ inversions that can be obtained. Our results highlight the predominant role of shear heating and the secondary role of erosion and accretion.

Our method of characterizing inverted peak temperatures extracted from numerical simulations can also be used to interpret peak temperature profiles acquired in natural IMS. Based on a set of metamorphic $P-T$ estimates, obtained along a cross-section through a major thrust zone, the same fitting function methodology can be applied. The maximum error associated with its application to our thousands of inverted peak temperature profiles analysed is only $\sim 10^{\circ} \mathrm{C}$ (i.e. lower than the uncertainty associated with the metamorphic temperature estimates). Any inverted metamorphic sequence can thus be approached by this type of analytical treatment in order to quantify the origins of its basic features.

Finally, we highlighted the crucial role of the rheology of the shear zone for the thermal budget around the thrust. In future studies, the implementation of non-linear viscosity would allow to examine the feedback between viscosity and temperature in detail. Furthermore, taking into account the depths and times associated with the peak temperatures resulting from the numerical experiments would provide many more constraints to interpret IMS from the field (i.e. $P-T-t$ data).

\section{ACKNOWLEDGEMENTS}

We are very grateful to C. Mottram and D. Grujic for their very helpful and constructive reviews that have substantially improved the manuscript. We also thank P. Tackley and D. May for the material support (2-D numerical models of the parametric study were run on the ETH Brutus cluster). P.Y. thanks the INSU Syster program that partially funded this work initiated during S.D.O's $\mathrm{PhD}$ thesis. This study was mainly performed during an active period of unemployment for S.D.O. She is particularly grateful to the University of Vienna for the financial support granted during the winter of 2015/2016.

\section{REFER E N CES}

Afonso, J.C. \& Ranalli, G., 2004. Crustal and mantle strengths in continental lithosphere: is the jelly sandwich model obsolete?, Tectonophysics, 394(3-4), 221-232.

Andreasson, P.G. \& Lagerblad, B., 1980. Occurrence and significance of inverted metamorphic gradients in the western Scandinavian Caledonides, J. Geol. Soc., Lond., 137(3), 219-230.

Arita, K., 1983. Origin of the inverted metamorphism of the Lower Himalayas, Central Nepal, Tectonophysics, 95(1-2), 43-60.

Artemieva, I.M. \& Mooney, W.D., 2001. Thermal thickness and evolution of Precambrian lithosphere: a global study, J. geophys. Res., 106(B8), $16387-16414$.

Barton, C.M. \& England, P.C., 1979. Shear heating at the Olympos (Greece) thrust and the deformation properties of carbonates at geological strain rates, Geol. Soc. Am. Bull., 90(5), 483-492.

Beaumont, C., Jamieson, R.A., Nguyen, M.H. \& Lee, B., 2001. Himalayan tectonics explained by extrusion of a low-viscosity crustal channel coupled to focused surface denudation, Nature, 414, 738-742.

Beaumont, C., Jamieson, R.A., Nguyen, M.H. \& Medvedev, S., 2004. Crustal channel flows: 1 . Numerical models with applications to the tectonics of the Himalayan-Tibetan orogen, J. geophys. Res., 109, B06406, doi:10.1029/2003JB002809.

Bird, P., 1978. Initiation of intracontinental subduction in the Himalaya, J. geophys. Res., 83(B10), 4975-4987. 
Bollinger, L., Avouac, J.P., Beyssac, O., Catlos, E.J., Harrison, T.M., Grove, M., Goffé, B. \& Sapkota, S., 2004. Thermal structure and exhumation history of the Lesser Himalaya in central Nepal, Tectonics, 23(5), TC5015, doi:10.1029/2003TC001564.

Bollinger, L., Henry, P. \& Avouac, J.P., 2006. Mountain building in the Nepal Himalaya: thermal and kinematic model, Earth planet. Sci. Lett., 244, 58-71.

Brewer, J., 1981. Thermal effects of thrust faulting, Earth planet. Sci. Lett., 56, 233-244.

Brun, J.P. \& Cobbold, P.R., 1980. Strain heating and thermal softening in continental shear zones: a review, J. Struct. Geol., 2(1-2), 149-158.

Brunel, M. \& Kienast, J.R., 1986. Étude pétro-structurale des chevauchements ductiles himalayens sur la transversales de l'Everest-Makalu (Népal oriental), Can. J. Earth Sci., 23, 1117-1137.

Burg, J.P. \& Gerya, T.V., 2005. The role of viscous heating in Barrovian metamorphism of collisional orogens: thermomechanical models and application to the Lepontine Dome in the Central Alps, J. Metamorph. Geol., 23(2), 75-95.

Burg, J.P. \& Schmalholz, S.M., 2008. Viscous heating allows thrusting to overcome crustal-scale buckling: numerical investigation with application to the Himalayan syntaxes, Earth planet. Sci. Lett., 274(1-2), 189-203.

Burg, J.P., Matte, P., Leyreloup, A. \& Marchand, J., 1984. Inverted metamorphic zonation and large-scale thrusting in the Variscan Belt: an example in the French Massif Central, Geol. Soc. Spec. Publ., 14(1), 47-61.

Bürgmann, R. \& Dresen, G., 2008. Rheology of the lower crust and upper mantle: evidence from rock mechanics, geodesy, and field observations, Ann. Rev. Earth planet. Sci., 36(1), 531-567.

Burov, E.B., 2003. The upper crust is softer than dry quartzite, Tectonophysics, 361(3), 321-326.

Burov, E.B. \& Watts, A.B., 2006. The long-term strength of continental lithosphere: "jelly sandwich" or "crème brûlée"?, Geol. Soc. Am. today, 16(1), 4-10.

Camacho, A., McDougall, I., Armstrong, R. \& Braun, J., 2001. Evidence for shear heating, Musgrave Block, central Australia, J. Struct. Geol., 23(6-7), 1007-1013.

Catlos, E.J., Harrison, T.M., Kohn, M.J., Grove, M., Ryerson, F.J., Manning, C.E. \& Upreti, B.N., 2001. Geochronologic and thermobarometric constraints on the evolution of the Main Central Thrust, central Nepal Himalaya, J. geophys. Res., 106(B8), 16 177-16 204.

Clauser, C. \& Huenges, E., 1995. Thermal conductivity of rocks and minerals, in Rocks Physics \& Phase Relations: A Handbook of Physical Constants, pp. 105-126, ed. Ahrens, T.J., AGU Reference Shelf. American Geoscience Union.

Copeland, P., Harrison, T.M., Hodges, K.V., Maruéjol, P., Le Fort, P. \& Pecher, A., 1991. An Early Pliocène thermal disturbance of the Main Central Thrust, Central Nepal: implications for Himalayan tectonics, J. geophys. Res., 96(B5), 8475-8500.

DeCelles, P.G., Robinson, D.M., Quade, J., Ojha, T.P., Garzione, C.N., Copeland, P. \& Upreti, B.N., 2001. Stratigraphy, structure, and tectonic evolution of the Himalayan fold-thrust belt in western Nepal, Tectonics, 20(4), 487-509.

Duprat-Oualid, S., Yamato, P. \& Pitra, P., 2013., Major role of shear heating in intracontinental inverted metamorphism: inference from a thermokinematic parametric study, Tectonophysics, 608, 812-831.

Duprat-Oualid, S., Yamato, P. \& Schmalholz, S.M., 2015. A dimensional analysis to quantify the thermal budget around lithospheric-scale shear zones, Terra Nova, 27(3), 163-168.

Duretz, T., Schmalholz, S.M., Podladchikov, Y.Y. \& Yuan, D.A., 2014. Physics-controlled thickness of shear zones caused by viscous heating: implication for crustal shear localization, Geophys. Res. Lett., 41, 49044911.

England, P. \& Molnar, P., 1993. The interpretation of inverted metamorphic isograds using simple physical calculations, Tectonics, 21(1), 145-157.

England, P.C. \& Thompson, A.B., 1984. Pressure-temperature-time paths of regional metamorphism: I. Heat transferduring the evolution of regions of thickened continental crust, J. Petrol., 25(4), 894-928.

Frank, W., Hoinkes, G., Miller, C., Purtscheller, F., Richter, W. \& Thöni, M., 1973. Relations between metamorphism and orogeny in a typical section of the Indian Himalayas, Tschermaks Mineralogische und Petrographische Mitteilungen, 20(4), 303-332.

Gerya, T.V. \& Yuen, D.A., 2003. Characteristics-based marker-in-cell method with conservative finite-differences schemes for modeling geological flows with strongly variable transport properties, Phys. Earth planet. Inter., 140(4), 293-318.

Ghent, E.D. \& Stout, M.Z., 1981. Metamorphism at the base of the Semail ophiolite, Southeastern Oman Mountains, J. geophys. Res., 86(B4), 25572571.

Gibson, H.D., Brown, R.L. \& Parrish, R.R., 1999. Deformation-induced inverted metamorphic field gradients: an example from the southeastern Canadian Cordillera, J. Struct. Geol., 21, 751-767.

Goscombe, B. \& Hand, M., 2000. Contrasting P-T paths in the Eastern Himalaya, Nepal: inverted Isograds in a paired metamorphic Mountain Belt, J. Petrol., 41(12), 1673-1719.

Graham, C.M. \& England, P., 1976. Thermal regimes and regional metamorphism in the vicinity of overthrust faults: an example of shear heating and inverted metamorphic zonation from southern California, Earth planet. Sci. Lett., 31(1), 142-152.

Graham, C.M. \& Powell, R., 1984. A garnet-hornblende geothermometer: calibration, testing, and application to the Pelona Schist, Southern California, J. Metamorph. Geol., 2(1), 13-31.

Grasemann, B. \& Vannay, J.C., 1999. Flow controlled inverted metamorphism in shear zones, J. Struct. Geol., 21, 743-750.

Grujic, D., Casey, M., Davidson, C., Hollister, L.S., Kündig, R., Pavlis, T. \& Schmid, S., 1996. Ductile extrusion of the higher Himalayan crystalline in Bhutan: evidence from quartz microfabrics, Tectonophysics, 260(1), $21-43$.

Harrison, T.M., Ryerson, F.J., Le Fort, P., Yin, A., Lovera, O.M. \& Catlos, E.J., 1997. A late Miocene-Pliocene origin for the Central Himalayan inverted metamorphism, Earth planet. Sci. Lett., 146, E1-E7.

Hartz, E.H. \& Podladchikov, Y.Y., 2008. Toasting the jelly sandwich: the effect of shear heating on lithospheric geotherms and strength, Geology, 36(4), 331-334.

Herman, F. et al., 2010. Exhumation, crustal deformation, and thermal structure of the Nepal Himalaya derived from the inversion of thermochronological and thermobarometric data and modeling of the topography, J. geophys. Res., 115(B6), B06407, doi:10.1029/2008JB006126.

Hubbard, M.S., 1996. Ductile shear as a cause of inverted metamorphism: example from the Nepal Himalaya, J. Geol., 104 (4), 493-499.

Huerta, A.D., Royden, L.H. \& Hodges, K.V., 1996. The interdepence of deformational and thermal processes in mountain belts, Science, 273, 637-639.

Huerta, A.D., Royden, L.H. \& Hodges, K.V., 1998. The thermal structure of collisional orogens as a response to accretion, erosion, and radiogenic heating, J. geophys. Res., 103(B7), 15 287-15 302.

Jain, A.K. \& Manickavasagam, R.M., 1993. Inverted metamorphism in the intracontinental ductile shear zone during Himalayan collision tectonics, Geology, 21(5), 407-410.

Jamieson, R.A., Beaumont, C., Hamilton, J. \& Fullsack, P., 1996. Tectonic assembly of inverted metamorphic sequences, Geology, 24(9), 839-842.

Jamieson, R.A., Beaumont, C., Fullsack, P. \& Lee, B., 1998. Barrovian regional metamorphism: where's the heat?, Geol. Soc. Spec. Publ., 138(1), 23-51.

Jamieson, R.A., Beaumont, C., Medvedev, S. \& Nguyen, M.H., 2004. Crustal channel flows: 2 . Numerical models with implications for metamorphism in the Himalayan-Tibetan orogen, J. geophys. Res., 109, B06407, doi:10.1029/2003JB002811.

Jamieson, R.A., Beaumont, C., Nguyen, M.H. \& Grujic, D., 2006. Provenance of the Greater Himalayan Sequence and associated rocks: predictions of channel flow models, Geol. Soc. Spec. Publ., 268(1), $165-182$.

Jaquet, Y. \& Schmalholz, S.M., 2017. Spontaneous ductile crustal shear zone formation by thermal softening and related stress, temperature and strain rate evolution, Tectonophysics, in press, doi:10.1016/j.tecto.2017.01.012.

Jaupart, C. \& Mareschal, J.C., 2012. Constraints on crustal heat production from heat flow data, in Treatise on Geochemistry, 2nd edn, Vol. 3: The Crust, pp. 65-84, ed. Rudnick, R.L., Permagon. 
Kaneko, Y., Katayama, I., Yamamoto, H., Misawa, K., Ishikawa, M., Rehman, H.U., Kausar, A.B. \& Shiraishi, K., 2003. Timing of Himalayan ultrahigh-pressure metamorphism: sinking rate and subduction angle of the Indian continental crust beneath Asia, J. Metamorph. Geol., 21(6), 589-599.

Kidder, S.B., Herman, F., Saleeby, J., Avouac, J.P., Ducea, M.N. \& Chapman, A., 2013. Shear heating as not a cause of inverted metamorphism, Geology, 41(8), 899-902.

Kohn, M.J., 2008. P-T-t data from central Nepal support critical taper and repudiate large-scale channel flow of the Greater Himalayan Sequence, Geol. Soc. Am. Bull., 120(3-4), 259-273.

Kohn, M.J., 2014. Himalayan metamorphism and its tectonic implications, Ann. Rev. Earth planet. Sci., 42, 381-419.

Kohn, M.J., Wieland, M.S., Parkinson, C.D. \& Upreti, B.N., 2004. Miocene faulting at plate tectonic velocity in the Himalaya of central Nepal, Earth planet. Sci. Lett., 228(8), 899-902.

Lachenbruch, A.H. \& Sass, J.H., 1980. Heat flow and Energetics of the San Andreas Fault Zone, J. geophys. Res., 85(B11), 6185-6222.

Lachenbruch, A.H. \& Sass, J.H., 1992. Heat flow from Cajon Pass, fault strength, and tectonic implications, J. geophys. Res., 97(B4), 4995-5015.

Law, R.D., Stahr, D.W., Francsis, M.K., Ashley, K.T., Grasemann, B \& Ahmad, T., 2013. Deformation temperatures and flow vorticities near the base of the Greater Himalayan Series, Sutlej Valley and Shimla Klippe, NW India, J. Struct. Geol., 54, 21-53.

Le Fort, P., 1975. Himalayas: the collided range. Present knowledge of the continental arc, Am. J. Sci., 275(A), 1-44.

Leloup, P.H. \& Kienast, J.R., 1993. High-temperature metamorphism in a major strike-slip zone: the Ailao Shan-Red River, People's Republic of China, Earth planet. Sci. Lett., 118(1), 213-234.

Leloup, P.H., Ricard, Y., Battaglia, J. \& Lacassin, R., 1999. Shear heating in intracontinental strike-slip shear zones: model and field examples, Geophys. J. Int., 136(1), 19-40.

Long, S.P., Gordon, S.M., Young, J.P. \& Soignard, E., 2016. Temperature and strain gradients through Lesser Himalayan rocks and across the Main Central Thrust, south-central Bhutan: implications for transport-parallel stretching and inverted metamorphism, Tectonics, 35(8), 1863-1891.

Mattauer, M., 1986. Intracontinental subduction, crust-mantle décollement and crustal-stacking wedge in the Himalayas and other collision belts. Geol. Soc. Spec. Publ., 19(1), 37-50.

Metcalfe, R.P., 1993. Pressure, temperature and time constraints on metamorphism across the Main Central Thrust zone and High Himalayan Slab in the Garhwal Himalaya, Geol. Soc. Spec. Publ., 74(1), 485-509.

Molnar, P. \& England, P., 1990. Temperatures, heat flux, and frictional stress near major thrust faults, J. geophys. Res., 95(B4), 4833-4856.

Mottram, C.M., Warren, C.J., Regis, D., Roberts, N.M.W., Harris, N.B.W., Argles, T.W. \& Parrish, R.R., 2014. Developping an inverted Barrovian sequence; insights from monazite petrochronology, Earth planet. Sci. Lett., 403, 418-431.

Nábělek, P.I. \& Nábělek, J.L., 2014. Thermal characteristics of the Main Himalayan Thrust and the Indian lower crust with implications for crustal rheology and partial melting in the Himalaya Orogen, Earth planet. Sci. Lett., 395, 116-123.

Nabelek, P.I., Liu, M. \& Sirbescu, M.L., 2001. Thermo-rheological, shear heating model for leucogranite generation, metamorphism, and deformation during the Proterozoic Trans-Hudson orogeny, Black Hills, South Dakota, Tectonophysics, 342(3), 371-388.

Nabelek, P.I., Whittington, A.G. \& Hofmeister, A.M., 2010. Strain heating as a mechanism for partial melting and ultrahigh temperature metamorphism in convergent orogens: implications of temperaturedependent thermal diffusivity and rheology, J. geophys. Res., 115, B12417, doi:10.1029/2010JB007727.

Patel, R.C., Adlakha, V., Singh, P., Kumar, Y. \& Lal, N., 2011. Geology, structural and exhumation of the Higher Himalayan Crystallines in $\mathrm{Ku}-$ maon Himalaya, India, J. Geol. Soc. India, 77(1), 47-72.

Paterson, M.S. \& Wong, T., 2005. Experimental Rock Deformation: The Brittle Field, 2nd edn, pp. 314, Springer.

Pavlis, T., 1986. The Role of Strain Heating in the Evolution of Megathrusts, J. geophys. Res., 91(B12), 12 407-12 422.
Peacock, S.M., 1987. Creation and preservation of subduction-related inverted metamorphic gradients, J. geophys. Res., 92(B12), 12 763-12 781.

Peacock, S.M., 1992. Blueschist-facies metamorphism, shear heating, and P-T-t paths in subduction shear zones, J. geophys. Res., 97(B12), $17693-$ 17707.

Pitra, P., Ballèvre, M. \& Ruffet, G., 2010. Inverted metamorphic field gradient towards a Variscan suture zone (Champtoceaux Complex, Armorican Massif, France), J. Metamorph. Geol., 28(2), 183-208.

Platt, J., 1975. Metamorphic and deformational processes in the Franciscan Complex, California: some insigths from the Catalina Schist terrane, Geol. Soc. Am. Bull., 86(10), 1337-1347.

Pollack, H.S. \& Chapman, D.N., 1977. Mantle heat flow, Earth planet. Sci. Lett., 34(2), 174-184.

Poirier, J.P., 1980. Shear localization and shear instability in materials in the ductile field, J. Struct. Geol., 2(1), 135-142.

Ranalli, G., 2003. How soft is the crust?, Tectonophysics, 361(3), 319-320.

Ranalli, G. \& Murphy, D.C., 1987. Rheological stratification of the lithosphere, Tectonophysics, 132(4), 281-295.

Regenauer-Lieb, K. \& Yuen, D.A., 1998. Rapid conversion of elastic energy into plastic shear heating during incipient necking of the lithosphere, Geophys. Res. Lett., 25(14), 2737-2740.

Regenauer-Lieb, K., Weinberg, R.F. \& Rosenbaum, G., 2006. The effect of energy feedbacks on continental strength, Nature, 442, 67-70.

Regenauer-Lieb, K., Rosenbaum, G. \& Weinberg, R.F., 2008. Strain localisation and weakening of the lithosphere during extension, Tectonophysics, 458, 96-104.

Reitan, P.H., 1968a. Frictional heat during metamorphism: quantitative evaluation of concentration of heat generation in time, Lithos, 1(2), 151-163.

Reitan, P.H., 1968b. Frictional heat during metamorphism: 2. quantitative evaluation of concentration of heat generation in space, Lithos, 1(3), 268274.

Royden, L.H., 1993. The steady state thermal structure of eroding orogenic belts and accretionary prisms, J. geophys. Res., 98(B3), 4487-4507.

Schmalholz, S.M., Kaus, B.J.P. \& Burg, J.P., 2009. Stress-strength relationship in the lithosphere during continental collision, Geology, 37(9), 775-778.

Scholz, C.H., 1979. Frictional metamorphism, argon depletion, and tectonic stress on the Alpine Fault, New Zealand, J. geophys. Res., 84(B12), 67706782.

Scholz, C.H., 1980. Shear heating and the state of stress on faults, J. geophys. Res., 85(B11), 6174-6184.

Searle, M.P. \& Rex, A.J., 1989. Thermal model for the Zankstar Himalaya, J. Metamorph. Geol., 7, 127-134.

Shi, Y. \& Wang, C.Y., 1987. Two-dimensional modeling of the P-T-t paths of regional metamorphism in simple overthrust terrains, Geology, 15(11), $1048-1051$.

Sobol', I.M., 1990. On sensitivity estimation for nonlinear mathematical models, Matematicheskoe Modelirovanie, 2(1), 112-118.

Srivastava, P. \& Mitra, G., 1994. Thrust geometrues and deep structure of the Outer and Lesser Himalaya, Kumaon and Garhwal (India): implications for the evolution of the Himalayan fold-and-thrust belt, Tectonics, 13, 89-109.

Stephenson, B.J., Waters, D.J. \& Searle, M.P., 2000. Inverted metamorphism and the Main Central Thrust: field relations and thermobarometric constraints from the Kishtwar Window, NW India Himala, J. Metamorph. Geol., 18, 571-590.

Stüwe, K., 1998. Heat sources of Cretaceous metamorphism in the Eastern Alps-a discussion, Tectonophysics, 287(1), 251-269.

Tucker, G.E. \& Bras, R., 2000. A stochastic approach to modeling the role of rainfall variability in drainage basin evolution, Water Resour. Res., 36, 1953-1964.

Tucker, G.E. \& Slingerland, R., 1994. Erosional dynamics, flexural isostasy, and long-lived escarpments: a numerical modeling study, J. geophys. Res., 99(B6), 12 229-12 243.

Turcotte, D. \& Schubert, G., 2002. Geodynamics, 2nd edn, pp. 456, Cambridge Univ. Press. 
Van Gool, J.A.M. \& Cawood, P.A., 1994. Frontal vs basal accretion and contrasting particle paths in metamorphic thrust belts, Geology, 22(1), 51-54.

Waples, D.W. \& Waples, J.S., 2004. A review and evaluation of specific heat capacities of rocks, minerals, and subsurface fluids. Part 1: Minerals and nonporous rocks, Nat. Resour. Res., 13(2), 97-122.

Williams, H. \& Smyth, W.R., 1973. Metamorphic aureoles beneath ophiolite suites and alpine peridotites, tectonic implications with west Newfoundland examples, Am. J. Sci., 273(7), 594-621.

Whipple, K.X. \& Tucker, G.E., 2002. Implications of sediment-fluxdependent river incision models for landscape evolution, J. geophys. Res., 107(B2), ETG 3-1-ETG 3-20.

Yin, A., 2006. Cenozoic tectonic evolution of the Himalayan orogen as constrained by along-strike variation of structural geometry, exhumation history, and foreland sedimentation, Earth-Sci. Rev., 76, 1-131.

Zhao, W., Nelson, K.D., Che, J., Quo, J., Lu, D., Wu, C. \& Liu, X., 1993. Deep seismic-reflection evidence for continental underthrusting beneath southern Tibet, Nature, 366, 557-559.

\section{SUPPORTING INFORMATION}

Supplementary data are available at GJIRAS online.

Appendix A: Sobol' first order global sensitivity index applied to the mathematical model of thermal process contributions.

Appendix B: Significance of inverted $T_{\text {peak }}$ profiles detailed for each feature.

Appendix C: Interdependencies between the features of inverted $T_{\text {peak }}$ profiles.

Please note: Oxford University Press is not responsible for the content or functionality of any supporting materials supplied by the authors. Any queries (other than missing material) should be directed to the corresponding author for the paper. 